NASA Technical Memorandum 107140

\title{
Further Evaluation of Traditional Icing Scaling Methods
}

David N. Anderson

Lewis Research Center

Cleveland, Ohio

Prepared for the

34th Aerospace Sciences Meeting and Exhibit

sponsored by the American Institute of Aeronautics and Astronautics

Reno, Nevada, January 15-18, 1996
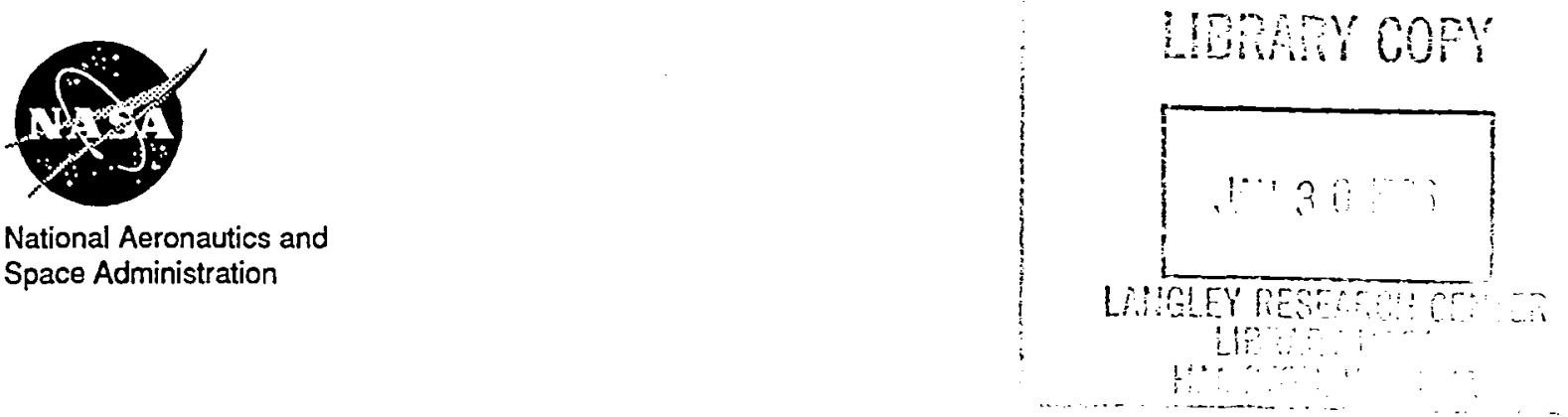
.

.

.

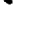




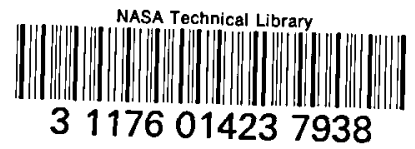

Further Evaluation of Traditional Icing Scaling Methods

\author{
David N. Anderson \\ NASA Lewis Research Center \\ Cleveland, $\mathrm{OH}$
}

\begin{abstract}
This report provides additional evaluations of two methods to scale icing test conditions; it also describes a hybrid technique for use when scaled conditions are outside the operating envelope of the test facility. The first evaluation is of the Olsen method which can be used to scale the liquid-water content in icing tests, and the second is the AEDC (Ruff) method which is used when the test model is less than full size. Equations for both scaling methods are presented in the paper, and the methods were evaluated by performing icing tests in the NASA Lewis Icing Research Tunnel (IRT). The Olsen method was tested using 53-cm-diameter NACA 0012 airfoils. Tests covered liquid-water-contents which varied by as much as a factor of 1.8. The Olsen method was generally effective in giving scale ice shapes which matched the reference shapes for these tests. The AEDC method was tested with NACA 0012 airfoils with chords from $18 \mathrm{~cm}$ to $53 \mathrm{~cm}$. The $53-\mathrm{cm}$-chord airfoils were used in reference tests, and 1/2- and $1 / 3$-scale tests were made at conditions determined by applying the AEDC scaling method. The scale and reference airspeeds were matched in these tests. The AEDC method was found to provide fairly effective scaling for $1 / 2$-size tests, but for $1 / 3$-size models, scaling was generally less effective. In addition to these two scaling methods, a hybrid approach was also tested in which the Olsen method was used to adjust the $L W C$ after size was scaled using the constant-Weber-number method. This approach was found to be an effective way to test when scaled conditions would otherwise be outside the capability of the test facility.
\end{abstract}

\section{Nomenclature}

$A_{c} \quad$ Accumulation parameter, dimensionless

$c$ Twice the airfoil leading-edge radius, $\mathrm{cm}$

$c_{p} \quad$ Specific heat, $\mathrm{cal} / \mathrm{g} \mathrm{K}$

$i_{c} \quad$ Convective film heat-transfer coefficient, $\mathrm{cal} / \mathrm{sec} \mathrm{m}^{2} \mathrm{~K}$

$k \quad$ Thermal conductivity, cal/sec $\mathrm{m} \mathrm{K}$

$K$ Inertia parameter, dimensionless

$K_{0} \quad$ Modified inertia parameter, dimensionless

LWC Liquid-water content, $\mathrm{g} / \mathrm{m}^{3}$

MVD Droplet median volume diameter, $\mu \mathrm{m}$

$n \quad$ Freezing fraction, dimensionless

$\mathrm{Nu} \quad$ Nusselt number, dimensionless

p Ambient static pressure, $n t / \mathrm{m}^{2}$

$p_{w} \quad$ Vapor pressure of water, $\mathrm{nt} / \mathrm{m}^{2}$

$\mathrm{Pr} \quad$ Prandtl number, dimensionless

$r \quad$ Recovery factor, dimensionless

$R_{a} \quad$ Gas constant for air, $287.0 \mathrm{nt} \mathrm{m} / \mathrm{kg} \mathrm{K}$
Re Reynolds number, dimensionless

Sc Schmidt number, dimensionless

$t$ Temperature, ${ }^{\circ} \mathrm{C}$

$T \quad$ Absolute temperature, $\mathrm{K}$

$V \quad$ Airspeed, $\mathrm{m} / \mathrm{s}$

We Weber number, dimensionless

$\beta_{0} \quad$ Droplet collection efficiency, dimensionless

$\delta \quad$ Droplet median volume diameter, $\mu \mathrm{m}$

$\phi \quad$ Droplet-energy transfer term in energy equation, $\mathrm{K}$

$\theta \quad$ Air-energy transfer term in energy equation, $\mathrm{K}$

$\lambda \quad$ Range of droplet, $\mathrm{cm}$

$\lambda_{\text {stokes }}$ Range of droplet obeying Stokes law, $\mathrm{cm}$

$\Lambda_{v} \quad$ Latent heat of vaporization, $\mathrm{cal} / \mathrm{g}$

$\rho \quad$ Density, $\mathrm{g} / \mathrm{cm}^{3}$

$\mu \quad$ Viscosity, $\mathrm{g} / \mathrm{cms}$

$\tau \quad$ Icing time, $\min$

Subscripts:

a Air

$\delta \quad$ Based on droplet size

$R \quad$ Reference size and conditions

st Static condition

surf Surface

$S \quad$ Scale size and conditions

tot Total condition

w Water

\section{Introduction}

This paper reports an evaluation of three methods to scale icing test conditions. The Olsen method ${ }^{1}$, which allows the $L W C$ to be scaled, and the AEDC method of Ruff ${ }^{2}$, which permits the model size to be scaled, have been evaluated previously ${ }^{1}$. A hybrid technique is also described and tested; it combines the Olsen method with a size-scaling method. Ice shapes obtained during icing tests in the NASA Lewis Icing Research Tunnel (IRT) will be shown, and comparisons made between scaled tests and reference tests.

Both the Olsen and AEDC methods were developed using traditional scaling approaches. In 1995 a constant-We method was proposed by Bilanin and Anderson ${ }^{3}$ which expanded on the traditional methods by adding the requirement that the scale and reference Weber number, We, match. While the method appeared to be effective, it had the disadvantage of requiring increasing airspeeds as model size was reduced. A further evaluation of this method is given in reference 4 . For many 
scaling situations, the restrictions of the constant-We method may not be acceptable, and other methods are required. This paper was motivated by this need.

The Olsen method applies to icing tests in which the facility is not capable of delivering the required cloud liquid-water content, $L W C$. Simply adjusting the accretion time, $\tau$, to maintain the product $L W C X \tau$ constant, as is frequently done, was shown in reference 1 to be inadequate if the shape of the ice is important. The Olsen method adjusts the temperature such that the freezing fraction, $n_{S}$, of the scale test matches that for the desired $L W C$. Reference I evaluated this method using cylinders of various diameters in the IRT. The present study expanded on that evaluation using NACA 0012 airfoils. Tests using the constant- $L W C$-x-time approach were also made, and results using the Olsen method will be compared with those using constant $L W C \times$ time.

The AEDC scaling method was derived by Ruff $^{2}$ for use when the model must be less than full size. This method permits the choice of scale airspeed as well as size, and past evaluations of the method ${ }^{1,2}$ have used scale velocities reduced from the reference values. Because airspeeds often do not need to be scaled, the study reported here evaluated the AEDC method with the scale velocity matched to the reference.

This paper presents the scaling equations for both the Olsen and AEDC methods. Results are given for tests of these procedures and of a hybrid method which combined the Olsen method with the constant-We method. The icing tests used NACA 0012 airfoils of $53.3 . \mathrm{cm}(2 \mathrm{l}-\mathrm{in})$ chord as the reference size. For reduced-size tests, models of $26.7-\mathrm{cm}(10.5-\mathrm{in})$ and $17.8-\mathrm{cm}(7-$ in) were used. Icing tests were conducted in the NASA Lewis Icing research Tunnel (IRT) with cloud conditions chosen to provide both rime- and glaze-ice accretions. Test airspeeds were 67 and $89 \mathrm{~m} / \mathrm{s}$ (150 and $200 \mathrm{mph}$ ).

\section{Description of Experiment}

NASA Lewis Icing Research Tunnel The IRT is shown in Figure 1. It has been described in reference 5 . The IRT has a test section width of $2.7 \mathrm{~m}(9 \mathrm{ft})$ and a height of $1.8 \mathrm{~m}(6 \mathrm{ft}$.) It is capable of operation at test-section airspeeds up to $160 \mathrm{~m} / \mathrm{s}$ (350 mph.) A refrigeration system permits accurate control of the test-section temperature from -40 to $4^{\circ} \mathrm{C}\left(-40\right.$ to $40^{\circ} \mathrm{F}$.) A water-spray system with 8 spray bars provides the ability to control test-section liquid-water content from .2 to $3 \mathrm{~g} / \mathrm{m}^{3}$ and droplet median volume diameters from 15 to $40 \mu \mathrm{m}$.

Two sets of spray nozzles, known as the mod-1 and standard nozzles, are used in the IRT to provide different ranges of liquid-water content and droplet size $\mathrm{e}^{6}$. For these tests, only the mod-1 nozzles were used.

Test Hardware Ice accretion was measured on NACA 0012 aiffoils mounted in the center of the IRT test section. The airfoils had chords of $53 \mathrm{~cm}(21 \mathrm{in}), 27 \mathrm{~cm}(10.5 \mathrm{in})$ and $18 \mathrm{~cm}$ (7 in). The 53-cm-chord airfoil was made of fiberglass while the 27- and $18-\mathrm{cm}$-chord aiffoils were machined from aluminum. Figure 2 shows the $53-\mathrm{cm}$-chord model as it was tested in the IRT. It was a full-span model mounted on the IRT turntable.

Figure 3 shows the $27-\mathrm{cm}$-chord airfoil in the IRT test section. This model had a span of $122 \mathrm{~cm}$ (48 in) and was supported by stands mounted to the floor and ceiling of the tunnel. To protect the airfoil from the transient icing spray cloud when the spray was initiated, a retractable shield was used. In Figure 3(a) the shield is in the raised, test, position, and in 3(b) it is lowered to prevent ice accretion during spray stabilization. The span and installation for the 18-cm- (7-in-) chord airfoil was identical. The shield could not be used with the 53-cm- (21-in-) chord airfoil because of mounting constraints.

All tests were made with the airfoils at $0^{\circ}$ angle of attack.

Test Procedure Tests were performed by first establishing the desired velocity and temperature. Water spray was then initiated. When the shield was used, it was raised when the spray conditions had stabilized, and the spray timer was started at that time. When the shield was not used, the spray time was started when spray was initiated, but because the spray $L W C$ had to ramp up from zero the spray time was increased by $.2 \mathrm{~min}$ for these tests. When the prescribed spray period was completed, the spray was shut off and the tunnel brought to idle to permit personnel entry into the test section to trace the ice shape.

The ice shape was recorded by first melting a thin slice through the ice normal to the model span-wise axis. The shape was then traced onto a cardboard template. These shapes were later digitized for computer storage of the coordinates for preparation of comparison plots. After the ice shape was recorded, the model was cleaned and the procedure repeated for the next spray condition.

Spray Stability For each of the tests, tunnel and cloud conditions were recorded at 2-sec intervals. Recording started with the initiation of the icing cloud for tests in which the model shield was not used (i.e., tests with the 53-cm- (21-in-) chord airfoil only) and with the lifting of the shield in all other tests. These data provided a means of determining the time to stabilize the spray in the case of the non-shielded tests and they also gave a check of the stability of the icing spray for both shielded and non-shielded starts.

Examples of these data are given in reference 4. For unshielded tests, the average liquid-water content reached the desired level in about 30 sec. After about a $3 \%$ overshoot of the $L W C$, stability at the set condition was reached in about $2 \mathrm{~min}$. This initial transient was taken into account by increasing the spray time by $.2 \mathrm{~min}$. When this was done, the integrated product of $L W C$ and time over the entire spray duration was within $\pm 2.5 \%$ of the product of the desired $L W C$ and time. For tests with the shield, the typical range of $L W C$ variation after the shield was 
raised was less than $\pm .4 \%$.

Typically about $3 \mathrm{~min}$ was required to achieve the required drop size with good stability when the shield was not used. For $95 \%$ of the spray time, the drop size was within $\pm 3 \mu \mathrm{m}$ of the correct value. For tests using the shield, the typical variation of $M V D$ was less than $\pm .5 \mu \mathrm{m}$ once the shield was raised to expose the model to the icing cloud.

The velocity was computed from the total pressure and the totalstatic differential pressure measured with each of two pitot probes located on either side of the entrance to the IRT test section. One pitot probe gave approximately $.7 \mathrm{~m} / \mathrm{s}(1.5 \mathrm{mph})$ higher velocity readings than the other. For the unshielded tests velocity variations throughout the test were less than $\pm 1.3 \mathrm{~m} / \mathrm{s}$ ( $\pm 3 \mathrm{mph}$ ).

When the shield was used to protect the model from the icing cloud during spray stabilization, the test-section blockage was higher with the shield lowered than when it was raised. This change required the tunnel operators to adjust the velocity when the shield was raised, and the velocity stability exhibited in the unshielded tests was never achieved. Fluctuations for the shielded tests were as much as $\pm 2.5 \mathrm{~m} / \mathrm{s}( \pm 5 \mathrm{mph})$.

Measurement Uncertainty All test conditions reported are averages taken over the duration of the test. For tests without the shield the average values of parameters were obtained after the stabilization of cloud conditions. Considering both the inaccuracy of the transducers used in the measurements and the fluctuations with time, the typical uncertainty in the liquid-water content was found to be less than $\pm 2.2 \%$, in the median volume diameter, less than $\pm 12.7 \%$, and in the tunnel airspeed, less than $\pm 4 \%$.

The tunnel temperature was the average of 11 thermocouples located on the turning vanes just upstream of the spray bars. These thermocouples have an uncertainty of about $\pm .6^{\circ} \mathrm{C}$ $\left( \pm 1^{\circ} \mathrm{F}\right)$. Furthermore, there is some stratification of temperature in the tunnel as shown in reference 4 . While the fluctuation of temperature with time was not great, there was a large variation from location to location. In this study, the test section temperature was not independently determined, and the temperatures reported here were found by averaging the 11 turning-vane thermocouples. Thus, although some mixing of the flow may reduce the stratification, the uncertainty in temperature for some test runs could have been as much as $\pm 3^{\circ} \mathrm{C}\left( \pm 6^{\circ} \mathrm{F}\right)$.

\section{Description of Scaling Methods}

Olsen Method In the Olsen method ${ }^{1}$, the model size, the water droplet size and the airspeed for the scale test are all matched to the respective values for the test conditions to be simulated. This matching of parameters assures that the droplet trajectory for the scale test will be the same as for the case to be simulated. In this paper the case being simulated will be called the reference case. The scale test will produce the correct quantity of ice if the accumulation parameter, $A_{c, s}$ matches that for the reference test conditions, $A_{c, R}$. Thus,

$$
L W C S_{s}^{\tau}=L W C_{R}^{\tau} R
$$

Equation (1) has often been used as a scaling technique by itself. This constant- $L W C$ - $\mathrm{x}$-time method equates the scale static temperature with the reference value. In the Olsen method, instead of matching the temperatures the scale and reference freezing fractions are equated. When this is done, it can be shown ${ }^{1}$ that the scale static temperature is given by

$$
t_{\pi S S}=t_{s, R}+\frac{h_{c}}{V \beta_{0} c_{p, w}}\left(\frac{\theta_{s}}{L W C_{S}}-\frac{\theta_{R}}{L W C_{R}}\right)
$$

where $\theta$ is the air energy transfer term in the Messinger energy equation?:

$$
\theta=t_{\text {arf }}-t_{\alpha \alpha}-r \frac{V^{2}}{2 c_{p \alpha}}+.693 \frac{\mathrm{gmK}}{\text { joule }} \Lambda_{v} \frac{p_{w \operatorname{mof}}-p_{w}}{p}
$$

In equation (3), $r$ is the recovery factor, taken as .875 in this study, and the factor $.693 \mathrm{gm} \mathrm{K} /$ joule is the ratio of the evaporative to the convective heat transfer coefficient.

The convective heat-transfer coefficient which Olsen used in equation (2) was

$$
h_{c}=1.05 \frac{k_{a}}{c} R e^{s}
$$

This is valid for the leading edge of an aifoil or cylinder. The collection efficiency, $\beta_{0}$, in equation (2) was found from the method of Langmuir and Blodgett ${ }^{8}$. The complete set of equations needed to calculate $\beta_{0}$ have also been given in reference 1 .

Equations (2) and (3) must be solved iteratively to find the static temperature. Although the Olsen method is not as simple to use as the constant- $L W C$-x-time method, the greater rigor of the Olsen analysis was shown in reference 1 to provide improved reproduction of ice shapes when $L W C$ is varied.

AEDC Method The AEDC scaling analysis was developed by Ruff $^{2}$ for tests in which the model size and, if necessary, the test velocity differ from the desired, or reference, tests. Ruff derived his scaling equations by equating the scale and reference droplet trajectories, the accumulation parameters and the heat balance. It gives results similar to those for the modified French analysis discussed in reference 1. For this study, in which the scale 
velocity was equated to the reference, the scaled conditions which resulted from application of the AEDC method were identical to those which would have been found from using the modified French method.

The scale and reference droplet energy transfer terms in the Messinger ${ }^{7}$ equation were matched to find the static scale temperature:

$$
t_{\alpha, S}=t_{\alpha A R}+\frac{V_{R}^{2}}{2 c_{p, w}}-\frac{v_{S}^{2}}{2 c_{p, w}}
$$

The scale static pressure was found from the total pressure for the test facility:

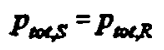

and

$$
P_{x, S}=p_{\text {axts }}\left(1-\frac{V_{S}^{2}}{2 R_{a} T_{a t S}}\right)
$$

The droplet size was found by matching the particle trajectories. Ruff did this by equating the scale modified inertia parameter, $K_{0}$, of Langmuir and Blogett' to that of the reference case:

$$
K_{0, S}=K_{0, R}
$$

where

$$
\begin{gathered}
K_{0}=\frac{\lambda}{\lambda_{\text {Stodas }}}(X-.125)+.125 \\
\frac{\lambda}{\lambda_{\text {Sceoses }}}= \\
\frac{.920-.132 \ln \left(R e_{8}\right)+.00445 \ln \left(R e_{8}\right)^{2}}{1-.0762 \ln \left(R e_{8}\right)+.0198 \ln \left(R e_{8}\right)^{2}+.000753 \ln \left(R e_{8}\right)^{3}}
\end{gathered}
$$

$$
K=\frac{\rho_{w} 8^{2} V}{18 \mu_{e} c}
$$

The scale drop size, $\delta_{S}$, was found in this study by solving equation (8), using equations (9) - (11), iteratively.

The scale liquid-water content, $L W C_{S}$, was determined by equating the freezing fractions, $n_{S}$ and $n_{R}$. Since the droplet energy terms were matched $\left(\phi_{S}=\phi_{R}\right)$ and the collection efficiency, $\beta_{0}$, must also match, reference 1 then showed that

$$
L W C_{S}=L W C_{R} \frac{\theta_{S}}{\theta_{R}} \frac{h_{c, S}}{h_{c, R}} \frac{V_{R}}{V_{S}}
$$

Following Ruff, this study used the convective heat transfer coefficient from $\mathrm{Kreith}^{9}$ in equation (12):

$$
h_{c}=\frac{1.14 \operatorname{Re}^{5} \operatorname{Pr}^{.4} k_{a}}{c}
$$

One form of the air energy transfer term, $\theta$, in equation (12) has been given as equation (3); however, Ruff developed a somewhat different expression:

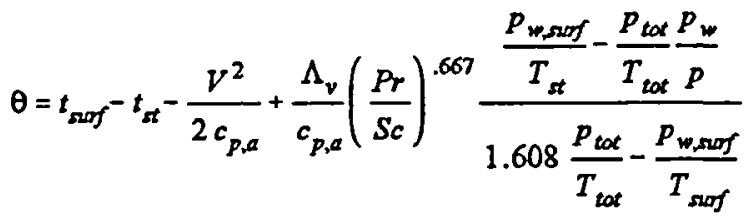

In equation (14), the vapor pressure, $p_{w, \text { surf }}$ is the vapor pressure at the surface temperature, $t_{\text {surf }}$ In this study, it was assumed that $t_{\text {surf }}=0^{\circ} \mathrm{C}$. Reference 10 published curve fits for the vapor pressures of water over ice and over water. These fits were used in this study to evaluate $\theta$ from equation (14). Equations (12) - (14) then gave the scale LWC for the AEDC method.

Finally, the time the model was exposed to the cloud was found by matching the scale and reference accumulation parameters, $A_{c, S}$ and $A_{c, R}$. Thus, the scale icing time was

$$
\tau_{S}=\tau_{R} \frac{c_{S}}{c_{R}} \frac{L W C_{R}}{L W C_{S}} \frac{V_{R}}{V_{S}}
$$

Hybrid Method Occasionally, the liquid-water content found after applying one of the methods for scaling size is not within the operating capability of the test facility. For this situation a hybrid-scale test can be performed by choosing a new scale liquid-water content that's within facility capabilities, then 
adjusting the temperature by applying the Olsen method. Tests of this hybrid approach were made using the constant-Webernumber method described in reference 4 with the Olsen method. The constant-Weber-number method was chosen for this study because it has been demonstrated elsewhere ${ }^{3,4}$ to provide effective scaling for most situations.

\section{Scaling Conditions}

Table I shows the four test cases used to evaluate the Olsen method. Conditions for the constant- $L W C$-x-time method are also shown, and results for this method will be presented for comparison with the Olsen method. All tests were made using a 53.3-cm- (21-in-) chord NACA 0012 airfoil. Cases 1 and 2 involved selecting scale liquid-water contents which were .8 and 1.4 times the reference $L W C$. For both cases, the airspeed was $67 \mathrm{~m} / \mathrm{s}(150 \mathrm{mph}), M V D, 30 \mu \mathrm{m}$ and reference $L W C, 1 \mathrm{~g} / \mathrm{m}^{3}$. The reference static temperature for case 1 was $-12.2^{\circ} \mathrm{C}\left(10^{\circ} \mathrm{F}\right)$ which gave a reference freezing fraction of .48 . For case 2 the reference static temperature was $-6.7^{\circ} \mathrm{C}\left(20^{\circ} \mathrm{F}\right)$; this increase of temperature over that of case 1 reduced the reference freezing fraction to .26. As noted above, the constant- $L W C$-x-time method matches the scale and reference temperatures; consequently, the scale freezing fractions do not match the reference. The Olsen method, however, adjusts the scale temperature so that the scale freezing fraction will match the reference.

Cases 3 and 4 in Table I used scale $L W C$ s of 1.27 and 1.82 times the reference $L W C$. For these cases the airspeed was 89 $\mathrm{m} / \mathrm{s}(200 \mathrm{mph}), M V D, 40 \mu \mathrm{m}$, and reference $L W C, .55 \mathrm{~g} / \mathrm{m}^{3}$. With a reference static temperature of $-15^{\circ} \mathrm{C}\left(5^{\circ} \mathrm{F}\right)$, case 3 had a reference freezing fraction of .71 . For case 4 the reference static temperature was $-6.7^{\circ} \mathrm{C}\left(20^{\circ} \mathrm{F}\right)$ which gave a reference freezing fraction of .28 .

The scaling conditions chosen to evaluate the AEDC method are given in Table II. For this study, tests were made with a 53.3cm-chord NACA 0012 airfoil as the reference model for all cases. Scale tests were made with both a $26.7-\mathrm{cm}-(10.5-\mathrm{in}-)$ chord and a 17.8-cm- (7-in-) chord 0012 to evaluate 1/2- and 1/3-size scaling, respectively. For all cases, the scale airspeeds were equal to the reference values. A reference $M V D$ of $40 \mu \mathrm{m}$ was chosen for all 6 test cases to insure that scaled $M V D$ 's were above the minimum achievable in the IRT. Cases 1.4 used an airspeed of $89 \mathrm{~m} / \mathrm{s}(200 \mathrm{mph})$ and a reference $L W C$ of $.55 \mathrm{~g} / \mathrm{m}^{3}$. These 4 cases differed only in temperature, and, therefore, freezing fraction. Cases 5 and 6 were tests with airspeeds of 67 $\mathrm{m} / \mathrm{s}(150 \mathrm{mph})$ and a reference $L W C$ of $.65 \mathrm{~g} / \mathrm{m}^{3}$. The test conditions gave a range of freezing fractions from .48 to .82 .

Table III shows the two cases studied which involved hybrid scaling. The reference tests for both cases were made with a 53.3-cm- (21-in-) chord NACA 0012 airfoil, an airspeed of 67 $\mathrm{m} / \mathrm{s}(150 \mathrm{mph})$, an $M W D$ of $30 \mu \mathrm{m}$, and an $L W C$ of $1 \mathrm{~g} / \mathrm{m}^{3}$. Note that case 1 had the same reference condition as case 1 in
Table I; however, because of different methods of calculation, the freezing fractions shown differed somewhat for the two cases. When the constant-We scaling was applied to a 1/2-size model (line 2 for each case in Table III), the $L W C$ which resulted, $1.16-1.17 \mathrm{~g} / \mathrm{m}^{3}$, was outside the IRT operating envelope for the required $M V D$. However, a reduction of the scale $L W C$ from 1.17 to $.8 \mathrm{~g} / \mathrm{m}^{3}$ gives a set of conditions which can be tested in the IRT. The conditions in the third line for each case resulted from applying Olsen scaling to find the appropriate temperature to test at $.8 \mathrm{~g} / \mathrm{m}^{3}$. For this evaluation, tests were made using the reference conditions and the hybrid scaling in line 3 for each case.

\section{Results}

The ice shapes recorded for the reference and scaling conditions of Tables I, II and III will be given here. The average conditions recorded for each test differed somewhat from the desired conditions, and these averages will be presented with each figure. Ice shapes were recorded at two locations along the model span: at the span-wise center of the tunnel $(91 \mathrm{~cm}$ (36 in) from the floor) and at $20 \mathrm{~cm}$ ( 8 in) above the center. Results at both locations will be given.

For tests with reduced-size models, the ice-shape coordinates have been divided by the appropriate scale factor to permit direct comparison of scale and reference ice shapes.

Olsen Method Figures 4 and 5 give the reference (solid lines) and scale ice shapes for the test conditions of case 1 in Table $I$. Figure 4 shows ice shapes using the constant-LWC-x-time method, and Figure 5, ice shapes for the OIsen method. Part (a) of each figure presents the ice shapes recorded at the tunnel center, and part (b) illustrates the shapes found $20 \mathrm{~cm}$ (8 in) above the tunnel center. The constant-LWC-x-time method produced ice shapes which matched fairly well when the $L W C$ was scaled from I to $.8 \mathrm{~g} / \mathrm{m}^{3}$, but the $1.4-\mathrm{g} / \mathrm{m}^{3}$ ice shape did not agree well with the $1-\mathrm{g} / \mathrm{m}^{3}$ reference shape at either location. When the Olsen method was used, however, ice shapes at both .8 and $1.4 \mathrm{~g} / \mathrm{m}^{3}$ matched the reference shape well at both locations.

Results for case 2 in Table I are given in Figures 6 and 7 for the constant- $L W C$-x-time and Olsen methods, respectively. This was a warmer condition than that of case 1 , and the horns shown in figures 4 and 5 are no longer apparent. The constant-LWC-xtime method provided only approximate matches of the reference ice shape for both scaled $L W C$ 's. The Olsen method gave somewhat better, but not perfect matches. In general, it has been found that warm glaze conditions such as this often give ice shapes that are difficult to reproduce ${ }^{1}$. This may be due in part to the fact that ice shapes are very sensitive to temperature at temperatures approaching freezing, and the differences between reference and scale temperatures were less than the uncertainty in temperature measurement. Thus, the quality of the Olsenmethod match may be as good as can be expected until improved 
temperature measurement can be achieved.

Figures 8 and 9 show the ice shapes for a mixed-ice condition. Again, it is evident that the Olsen method (Figure 9) provided more effective scaling than the constant- $L W C$-x-time method (Figure 8). However, the constant-LWC-x-time method appeared to scale adequately from an $L W C$ of .7 to a value of 1 $\mathrm{g} / \mathrm{m}^{3}$.

Finally, case 4 of Table I gave the ice shapes of Figures 10 and 11. These conditions again produced a warm-glaze ice similar in appearance to that in Figures 6 and 7 (case 2). The constantLWC-x-time method (Figure 10) gave reasonable agreement between the .55 and the $.7 \mathrm{~g} / \mathrm{m}^{3}$ tests, but the $1 \mathrm{-g} / \mathrm{m}^{3}$ shape did not match the other two. The scale ice shapes for the Olsen method (Figure 11) were only approximate matches of the reference, but, again, the agreement is probably as good as the ability to reproduce shapes at such conditions.

AEDCMethod Case 1 in Table II gave a mixed-ice accretion as shown in Figure 12. For these conditions the AEDC method produced scaled ice shapes for both the 1/2- and 1/3-size tests which fairly faithfully matched the reference shape.

For the tests whose results are presented in Figure 13 (case 2 in Table II), the temperature was raised $3^{\circ} \mathrm{C}\left(5^{\circ} \mathrm{F}\right)$ over that for Figure 12. A hom-glaze ice shape was produced by the reference conditions. This shape was only approximated by the scale tests at $1 / 2$ and $1 / 3$ size with horns less distinct than the reference.

Another horn-glaze case is given in Figure 14. This represents the results for case 3 in Table I. Here the temperature has again been increased $3^{\circ} \mathrm{C}\left(5^{\circ} \mathrm{F}\right)$ over that of case 2 (Figure 13). At both the tunnel center and at the 20-cm- (8-in-) above-center location, the reference and 1/2-size scale ice shapes nearly matched while the 1/3-size shape produced a shape with a much greater hom angle than the reference.

With a final increase in temperature (case 4 in Table II), the warm-glaze shape shown in Figure 15 was produced. Given the difficulty in repeating ice shapes at warm-glaze conditions, the shapes from both the 1/2- and 1/3-size scaling tests appeared to match the reference shape fairly well.

Results for the fifth case in Table II are shown in Figure 16. Both the 1/2- and 1/3-size scale tests gave shapes that failed to reproduce the distinct horns of the reference shape. However, the two scale tests gave shapes that matched each other fairiy well, and they reproduced in approximate form the general shape and size of the reference shape.

Finally, Figure 17 shows the ice shapes for case 6 in Table II. This case is a repeat of case 5 except that the temperature has been raised $3^{\circ} \mathrm{C}\left(5^{\circ} \mathrm{F}\right)$. Once again, the $1 / 2$ - and $1 / 3$-size scale tests gave shapes that matched each other but neither accurately reproduced the reference shape.
In reference 4 the constant-We scaling method was evaluated using many of the same test cases used here for the AEDC method. A comparison of the results from those tests indicates that the AEDC method was generally less effective in matching reference ice shapes than the constant-We method.

Hybrid Method The hybrid method tested involved application of Olsen scaling to the results of the constant-We method of reference 3 to provide an alternate $L W C$ to the value required by that method. For this study, the constant-We method was applied to scale to $1 / 2$ size, then the Olsen method was used to reduce the test $L W C$ to $.8 \mathrm{~g} / \mathrm{m}^{3}$. Only two cases will be presented.

Results for case 1 in Table III are given in Figure 18. The reference conditions for this case were the same as for case 1 of Table I. At the tunnel center, the scale ice shape matched the reference at least as well as the Olsen method; those results were given in Figure 4. At the $20-\mathrm{cm}$ - (8-in-) above-center location, the scale shape was not as successful at reproducing the reference.

A warmer condition is shown in Figure 19. This figure gives the result for case 2 in Table III. For this case, the distinct homs of the reference shapes of Figures 4 and 18 have been lost. The 1/2-size scale test correctly reproduced the reference shape at both the tunnel center and 20-cm (8-in-) above-center locations.

For all the scaling results presented, the uncertainty in temperature measurement is a concern, particularly for the warmer glaze conditions. As shown by the Olsen scaling results, changes in temperature of a few degress can have a noticeable effect on ice shape. With better control of temperature, it is possible that scale ice shapes would have matched reference shapes better. Although uncertainty in drop size was large, this factor was judged to be less critical than temperature.

\section{Concluding Remarks}

Tests have been made to evaluate three methods to scale icing test conditions. The first was the Olsen method which provides an adjustment for the temperature to maintain a constant freezing fraction when the liquid-water content is varied. All other scale parameters, including size, match the reference values. It is applied to situations in which the desired $L W C$ cannot be tested due, for example, to test facility limitations. The second method was the AEDC method developed by Ruff. This method permits the use of reduced-size models for testing, and the user may select a test airspeed. For this study, the scale airspeed was equated to the reference value. Finally, the third method was a hybrid scaling approach in which the constant-We method of reference 3 was applied, then the $L W C$ was altered using the Olsen method.

All tests were performed with NACA 0012 airfoils at $0^{\circ}$ angle of attack. The reference tests used a 53.3-cm- (21-in-) chord model and reduced-size tests used $26.7-\mathrm{cm}-(10.5-\mathrm{in}-)$ and $17.8-$ 
cm- (7-in-) chord models. Test conditions produced a variety of ice shapes including mixed, horm-glaze and warm-glaze.

Reference tests were performed, the ice shape recorded, scaled tests made and the scale ice shapes compared with the reference. The evaluation of the scaling methods was based on how well the scaled shape matched the reference shape.

The Olsen method was tested with scale $L W C$ s which ranged from 8 to 1.8 of the reference $L W C$. This method produced ice shapes which generally matched the reference shapes for all types of ice tested. These results were compared with some from the more-commonly used law, $L W C \times$ time $=$ constant. The latter approach was generally less successful than the Olsen method, but is simpler to apply. In situations for which a fairly accurate prediction of ice shape is not required, and for small changes in $L W C$ from the reference value, $L W C \times$ time $=$ constant may be useful. When the scale $L W C$ is significantly different from the desired value, or when the scale ice shape must give a fairly accurate prediction, the Olsen method is superior. It requires only that the scale temperature be adjusted so that the scale freezing fraction match that of the reference case.

The AEDC method was found to give scaled ice shapes that usually approximated the reference for $1 / 2$-size scaling. When the model size was reduced to $1 / 3$ the reference, the resulting ice shapes tended to be poorer simulations of the reference shapes. It's worth noting that for the constant-velocity scaling of this study the modified French method described in reference 1 would have given scaling conditions identical to those for the AEDC method.

While the AEDC method did not simulate the reference ice shape as effectively as the constant-We method evaluated in reference 4 , it has one notable advantage: the constant-We method requires a scale velocity that increases with decreasing scale size. This characteristic makes it difficult to use the constant-We method when tests at high airspeeds are to be simulated. When model size does not need to be scaled to less than half the reference size, the scale and reference velocities can be matched, and the scale test does not need to give an exact simulation of the reference ice shape, the AEDC method (or, equivalently, the modified French method) should be considered.

The last method evaluated was a hybrid method using both the constant-We method and the Olsen method. It is often the case that when a scaling method is used to determine appropriate reduced-size test conditions, the resulting $L W C$ is not within the operating envelope of the test facility. The remedy is to choose an LWC which is within the facility envelope and is close the originally-scaled $L W C$. The originally-scaled temperature can then be adjusted using the Olsen method such that the same freezing fraction is achieved. Tests using this hybrid approach confirmed the validity of this technique when applied along with the constant-We method.

Better precision in the measurement and control of the tunnel temperature is needed to yield greater confidence in the results of scaling tests. In this study, the uncertainty in tunnel temperature was as much as $\pm 3^{\circ} \mathrm{C}\left( \pm 6^{\circ} \mathrm{F}\right)$. Temperature changes of this magnitude can have a measurable effect on ice shape.

The scaling methods described here are only applicable to tests of straight-wing sections; an understanding of the physics of ice accretion on swept wings has not yet been developed, and this understanding is needed before swept-wing scaling methods can be formulated

\section{References}

1. Anderson, David N.: "Methods for Scaling Icing Test Conditions," AIAA 95-0540 and NASA TM 106827, January, 1995.

2. Ruff, G.A.: "Analysis and Verification of the Icing Scaling Equations," AEDC-TR-85-30, Vol 1 (Rev), March, 1986.

3. Bilanin, Alan J. and Anderson, David N.: "Ice Accretion with Varying Surface Tension," AIAA 95-0538 and NASA TM 106826, January, 1995.

4. Anderson, David N.: "Evaluation of Constant-WeberNumber Scaling for Icing Tests," AIAA 96-0636, January, 1996.

5. Soeder, Ronald H. and Andracchio, Charles, R., "NASA Lewis Icing Research Tunnel User Manual," NASA TM 102319, June 1990.

6. Ide, Robert F., "Liquid Water Content and Droplet Size Calibration of the NASA Lewis Icing Research Tunnel, "NASA TM 102447, Jan 1990.

7. Messinger, B.L., "Equilibrium Temperature of an Unheated Icing Surface as a Function of Airspeed," J. Aeron. Sci. 20 No. 1, Jan. 1953, pp 29-42.

8. Langmuir, Irving and Blodgett, Katharine B.: "A Mathematical Investigation of Water Droplet Trajectories," Army Air Forces Technical Report No. 5418, February, 1946.

9. Kreith, Frank, Principles of Heat Transfer, International Textbook Co., Scranton, 1958.

10. Pruppacher, Hans R. and Klett, James D., Microphysics of Clouds and Precipitation, Reidel, Boston, 1980. 
Table I. Scaling Conditions for Constant-LWCXTime and Olsen Methods NACA 0012 Airfoil Chord, $53.3 \mathrm{~cm}$ (21 in)

\begin{tabular}{|c|c|c|c|c|c|c|c|c|c|c|c|}
\hline case & scalin & $\begin{array}{l}\mathrm{t}_{\mathrm{st}} \\
{ }^{\circ} \mathrm{C}\end{array}$ & $\begin{array}{l}t_{\text {Lot }} \\
{ }^{\circ} \mathrm{C}\end{array}$ & $\begin{array}{l}t_{s t} \\
{ }^{\circ} \mathrm{F}\end{array}$ & $\begin{array}{l}t_{\text {Lot }} \\
{ }^{\circ} \mathrm{F}\end{array}$ & $\begin{array}{c}\mathrm{V} \\
\mathrm{m} / \mathrm{sec}\end{array}$ & $\begin{array}{c}\mathrm{V} \\
\mathrm{mph}\end{array}$ & $\begin{array}{c}M V D \\
\mu \mathrm{m}\end{array}$ & $\begin{array}{l}L W C, \\
\mathrm{~g} / \mathrm{m}^{3}\end{array}$ & $\begin{array}{l}\text { time, } \\
\min \end{array}$ & $n$ \\
\hline 1 & $\begin{array}{c}\text { reference } \\
\text { Const- } L W C x \text { Time: } .8 L W C_{\mathrm{R}} \\
\text { Const- } L W C x \text { Time: } 1.4 L W C_{\mathrm{R}} \\
\text { Olsen Method: } .8 L W C_{\mathrm{R}} \\
\text { Olsen Method: } 1.4 L W C_{\mathrm{R}}\end{array}$ & $\begin{array}{l}-12.2 \\
-12.2 \\
-12.2 \\
-10.3 \\
-15.1 \\
\end{array}$ & $\begin{array}{r}-10.0 \\
-10.0 \\
-10.0 \\
-8.1 \\
-12.8 \\
\end{array}$ & $\begin{array}{r}10.0 \\
10.0 \\
10.0 \\
13.4 \\
4.9 \\
\end{array}$ & $\begin{array}{r}14.0 \\
14.0 \\
14.0 \\
17.5 \\
8.9 \\
\end{array}$ & $\begin{array}{l}67.1 \\
67.1 \\
67.1 \\
67.1 \\
67.1 \\
\end{array}$ & $\begin{array}{l}150.0 \\
150.0 \\
150.0 \\
150.0 \\
150.0 \\
\end{array}$ & $\begin{array}{l}30.0 \\
30.0 \\
30.0 \\
30.0 \\
30.0 \\
\end{array}$ & $\begin{array}{r}1.00 \\
.80 \\
1.40 \\
.80 \\
1.40 \\
\end{array}$ & $\begin{array}{l}7.29 \\
9.11 \\
5.21 \\
9.11 \\
5.21 \\
\end{array}$ & $\begin{array}{l}.48 \\
.57 \\
.39 \\
.48 \\
.48\end{array}$ \\
\hline 2 & $\begin{array}{c}\text { reference } \\
\text { Const- } L W C x \text { Time: } .8 L W C_{\mathrm{R}} \\
\text { Const- } L W C x \text { Time: } 1.4 L W C_{\mathrm{R}} \\
\text { Olsen Method: } .8 L W C_{\mathrm{R}} \\
\text { Olsen Method: } 1.4 L W C_{\mathrm{R}}\end{array}$ & $\begin{array}{l}-6.7 \\
-6.7 \\
-6.7 \\
-5.7 \\
-8.1\end{array}$ & $\begin{array}{l}-4.4 \\
-4.4 \\
-4.4 \\
-3.5 \\
-5.8\end{array}$ & $\begin{array}{l}20.0 \\
20.0 \\
20.0 \\
21.7 \\
17.5\end{array}$ & $\begin{array}{l}24.0 \\
24.0 \\
24.0 \\
25.7 \\
21.5\end{array}$ & $\begin{array}{l}67.1 \\
67.1 \\
67.1 \\
67.1 \\
67.1\end{array}$ & $\begin{array}{l}150.0 \\
150.0 \\
150.0 \\
150.0 \\
150.0\end{array}$ & $\begin{array}{l}30.0 \\
30.0 \\
30.0 \\
30.0 \\
30.0\end{array}$ & $\begin{array}{r}1.00 \\
.80 \\
1.40 \\
.80 \\
1.40\end{array}$ & $\begin{array}{l}7.29 \\
9.11 \\
5.21 \\
9.11 \\
5.21\end{array}$ & $\begin{array}{l}.26 \\
.30 \\
.20 \\
.25 \\
.25\end{array}$ \\
\hline 3 & $\begin{array}{c}\text { reference } \\
\text { Const- } L W C x \text { Time: } 1.27 L W C_{\mathrm{R}} \\
\text { Const- } L W C x \text { Time: } 1.82 L W C_{\mathrm{R}} \\
\text { Olsen Method: } 1.27 L W C_{\mathrm{R}} \\
\text { Olsen Method: } 1.82 L W C_{\mathrm{R}}\end{array}$ & $\begin{array}{l}-15.0 \\
-15.0 \\
-15.0 \\
-17.6 \\
-22.2\end{array}$ & $\begin{array}{l}-11.0 \\
-11.0 \\
-11.0 \\
-13.6 \\
-18.3\end{array}$ & $\begin{array}{r}5.0 \\
5.0 \\
5.0 \\
.4 \\
-8.0\end{array}$ & $\begin{array}{r}12.2 \\
12.2 \\
12.2 \\
7.5 \\
-.9\end{array}$ & $\begin{array}{l}89.4 \\
89.4 \\
89.4 \\
89.4 \\
89.4\end{array}$ & $\begin{array}{l}200.0 \\
200.0 \\
200.0 \\
200.0 \\
200.0\end{array}$ & $\begin{array}{l}40.0 \\
40.0 \\
40.0 \\
40.0 \\
40.0\end{array}$ & $\begin{array}{r}.55 \\
.70 \\
1.00 \\
.70 \\
1.00\end{array}$ & $\begin{array}{l}9.95 \\
7.82 \\
5.47 \\
7.82 \\
5.47\end{array}$ & $\begin{array}{l}.71 \\
.60 \\
.47 \\
.70 \\
.70\end{array}$ \\
\hline 4 & $\begin{array}{c}\text { reference } \\
\text { Const- } L W C x \text { Time: } 1.27 L W C_{\mathrm{R}} \\
\text { Const- } L W C x \text { Time: } 1.82 L W C_{\mathrm{R}} \\
\text { Olsen Method: } 1.27 L W C_{\mathrm{R}} \\
\text { Olsen Method: } 1.82 L W C_{\mathrm{R}}\end{array}$ & $\begin{array}{l}-6.7 \\
-6.7 \\
-6.7 \\
-7.6 \\
-9.2\end{array}$ & $\begin{array}{l}-2.7 \\
-2.7 \\
-2.7 \\
-3.6 \\
-5.2\end{array}$ & $\begin{array}{l}20.0 \\
20.0 \\
20.0 \\
18.4 \\
15.4\end{array}$ & $\begin{array}{l}27.2 \\
27.2 \\
27.2 \\
25.6 \\
22.6\end{array}$ & $\begin{array}{l}89.4 \\
89.4 \\
89.4 \\
89.4 \\
89.4\end{array}$ & $\begin{array}{l}200.0 \\
200.0 \\
200.0 \\
200.0 \\
200.0\end{array}$ & $\begin{array}{l}40.0 \\
40.0 \\
40.0 \\
40.0 \\
40.0\end{array}$ & $\begin{array}{r}.55 \\
.70 \\
1.00 \\
.70 \\
1.00\end{array}$ & $\begin{array}{l}9.95 \\
7.82 \\
5.47 \\
7.82 \\
5.47\end{array}$ & $\begin{array}{l}.28 \\
.23 \\
.19 \\
.28 \\
.28\end{array}$ \\
\hline
\end{tabular}

Table II. Scaling Conditions for AEDC Method

\begin{tabular}{|c|c|c|c|c|c|c|c|c|c|c|c|c|c|}
\hline case & $\begin{array}{c}\text { scaling } \\
\text { situation }\end{array}$ & $\begin{array}{c}\text { chord, } \\
\text { cm }\end{array}$ & $\begin{array}{c}\text { chord, } \\
\text { in }\end{array}$ & $\begin{array}{l}t_{s t} \\
{ }^{\circ} \mathrm{C}\end{array}$ & $\begin{array}{l}t_{\text {toto }} \\
{ }^{\circ} \mathrm{C}\end{array}$ & $\begin{array}{l}t_{s t} \\
{ }^{\circ} F\end{array}$ & tot: & $\begin{array}{c}\mathrm{V} \\
\mathrm{m} / \mathrm{sec}\end{array}$ & $\begin{array}{c}\mathrm{V} \\
\mathrm{mph}\end{array}$ & $\begin{array}{c}M V D, \\
\mu \mathrm{m}\end{array}$ & $\begin{array}{l}L W C, \\
\mathrm{~g} / \mathrm{m}^{3}\end{array}$ & $\begin{array}{l}\text { time, } \\
\min \end{array}$ & $n$ \\
\hline \multirow[t]{3}{*}{1} & & 53.3 & 21 & 5.0 & 1.0 & 5.0 & 12.2 & 89.4 & 200.0 & 40.0 & .55 & 9.95 & .82 \\
\hline & $1 / 2$ size & 26.7 & 10.5 & -15.0 & -11.0 & 5.0 & 12.2 & 89.4 & 200.0 & 26.0 & .78 & 3.53 & .82 \\
\hline & 1/3 size & 17.8 & 7 & -15.0 & -11.0 & 5.0 & 12.2 & 89.4 & 200.0 & 20.2 & .95 & 1.92 & .82 \\
\hline \multirow[t]{3}{*}{2} & reference & 53.3 & 21 & -12.2 & -8.2 & 10.0 & 17.2 & 89.4 & 200.0 & 40.0 & .55 & 9.95 & .66 \\
\hline & $1 / 2$ size & 26.7 & 10.5 & -12.2 & -8.2 & 10.0 & 17.2 & 89.4 & 200.0 & 26.0 & .78 & 3.53 & .66 \\
\hline & $1 / 3$ size & 17.8 & 7 & -12.2 & -8.2 & 10.0 & 17.2 & 89.4 & 200.0 & 20.2 & .95 & 1.92 & .66 \\
\hline \multirow[t]{3}{*}{3} & reference & 53.3 & 21 & -9.4 & -5.5 & 15.0 & 22.2 & 89.4 & 200.0 & 40.0 & .55 & 9.95 & .49 \\
\hline & $1 / 2$ size & 26.7 & 10.5 & -9.4 & -5.5 & 15.0 & 22.2 & 89.4 & 200.0 & 26.0 & .78 & 3.53 & .49 \\
\hline & $1 / 3$ size & 17.8 & 7 & -9.4 & -5.5 & 15.0 & 22.2 & 89.4 & 200.0 & 20.2 & .95 & 1.92 & .49 \\
\hline \multirow[t]{3}{*}{4} & reference & 53.3 & 21 & -6.7 & -2.7 & 20.0 & 27.2 & 89.4 & 200.0 & 40.0 & .55 & 9.95 & .32 \\
\hline & $1 / 2$ size & 26.7 & 10.5 & -6.7 & -2.7 & 20.0 & 27.2 & 89.4 & 200.0 & 26.0 & .77 & 3.53 & .32 \\
\hline & $1 / 3$ size & 17.8 & 7 & -6.7 & -2.7 & 20.0 & 27.2 & 89.4 & 200.0 & 20.2 & .95 & 1.92 & .32 \\
\hline \multirow[t]{3}{*}{5} & reference & 53.3 & 21 & -11.1 & -8.9 & 12.0 & 16.0 & 67.1 & 150.0 & 40.0 & .65 & 11.22 & .65 \\
\hline & $1 / 2$ size & 26.7 & 10.5 & -11.1 & -8.9 & 12.0 & 16.0 & 67.1 & 150.0 & 26.0 & .92 & 3.97 & .65 \\
\hline & $1 / 3$ size & 17.8 & 7 & -11.1 & -8.9 & 12.0 & 16.0 & 67.1 & 150.0 & 20.2 & 1.13 & 2.16 & .65 \\
\hline \multirow[t]{3}{*}{6} & reference & 53.3 & 21 & -8.3 & -6.1 & 17.0 & 21.0 & 67.1 & 150.0 & 40.0 & .65 & 11.22 & .48 \\
\hline & $1 / 2$ size & 26.7 & 10.5 & -8.3 & -6.1 & 17.0 & 21.0 & 67.1 & 150.0 & 26.0 & .92 & 3.97 & .48 \\
\hline & $1 / 3$ size & 17.8 & 7 & -8.3 & -6.1 & 17.0 & 21.0 & 67.1 & 150.0 & 20.2 & 1.13 & 2.16 & .48 \\
\hline
\end{tabular}


Table III. Scaling Conditions for Hybrid Method

(Olsen Method Used to Alter $L W C$ after Scaling With Constant-We Method)

\begin{tabular}{|c|c|c|c|c|c|c|c|c|c|c|c|c|c|}
\hline case & $\begin{array}{c}\text { scaling } \\
\text { situation }\end{array}$ & $\begin{array}{c}\text { chord, } \\
\mathrm{cm}\end{array}$ & $\begin{array}{c}\text { chord, } \\
\text { in }\end{array}$ & $\begin{array}{l}t_{s t} \\
{ }^{\circ} \mathrm{C}\end{array}$ & $\begin{array}{l}\mathrm{t}_{\text {tot }} \\
{ }^{\circ} \mathrm{C}\end{array}$ & $\begin{array}{l}\mathrm{t}_{\mathrm{st}} \\
{ }^{\circ} \mathrm{F}\end{array}$ & $\begin{array}{l}\mathrm{t}_{\text {tot }} \\
{ }^{\circ} \mathrm{F}\end{array}$ & $\begin{array}{c}\mathrm{V} \\
\mathrm{m} / \mathrm{sec}\end{array}$ & $\begin{array}{c}\mathrm{V}, \\
\mathrm{mph}\end{array}$ & $\begin{array}{c}M V D \\
\mu \mathrm{m}\end{array}$ & $\begin{array}{l}L W C, \\
\mathrm{~g} / \mathrm{m}^{3}\end{array}$ & $\begin{array}{c}\text { time, } \\
\min \end{array}$ & $n$ \\
\hline \multirow[t]{3}{*}{1} & reference & 53.3 & 21 & -12.2 & -10.0 & 10.0 & 14.0 & 67.1 & 150.0 & 30.0 & 1.00 & 7.29 & .55 \\
\hline & $1 / 2$ size $-W e$ & 26.7 & 10.5 & -12.6 & -8.8 & 9.3 & 16.2 & 87.7 & 196.3 & 17.5 & 1.17 & 2.38 & .55 \\
\hline & $1 / 2$ size $-W e+$ Olsen & 26.7 & 10.5 & -9.7 & -5.9 & 14.5 & 21.5 & 87.7 & 196.3 & 17.5 & .80 & 3.48 & .55 \\
\hline \multirow[t]{3}{*}{2} & reference & $\overline{53.3}$ & 21 & -9.4 & -7.2 & 15.0 & 19.0 & 67.1 & 150.0 & 30.0 & 1.00 & 7.29 & .42 \\
\hline & $1 / 2$ size $-W e$ & 26.7 & 10.5 & -9.8 & -6.0 & 14.3 & 21.2 & 87.7 & 196.2 & 17.5 & 1.16 & 2.41 & .42 \\
\hline & $1 / 2$ size $-W e+$ Olsen & 26.7 & 10.5 & -7.7 & -3.9 & 18.1 & 25.0 & 87.7 & 196.2 & 17.5 & .80 & 3.50 & .42 \\
\hline
\end{tabular}

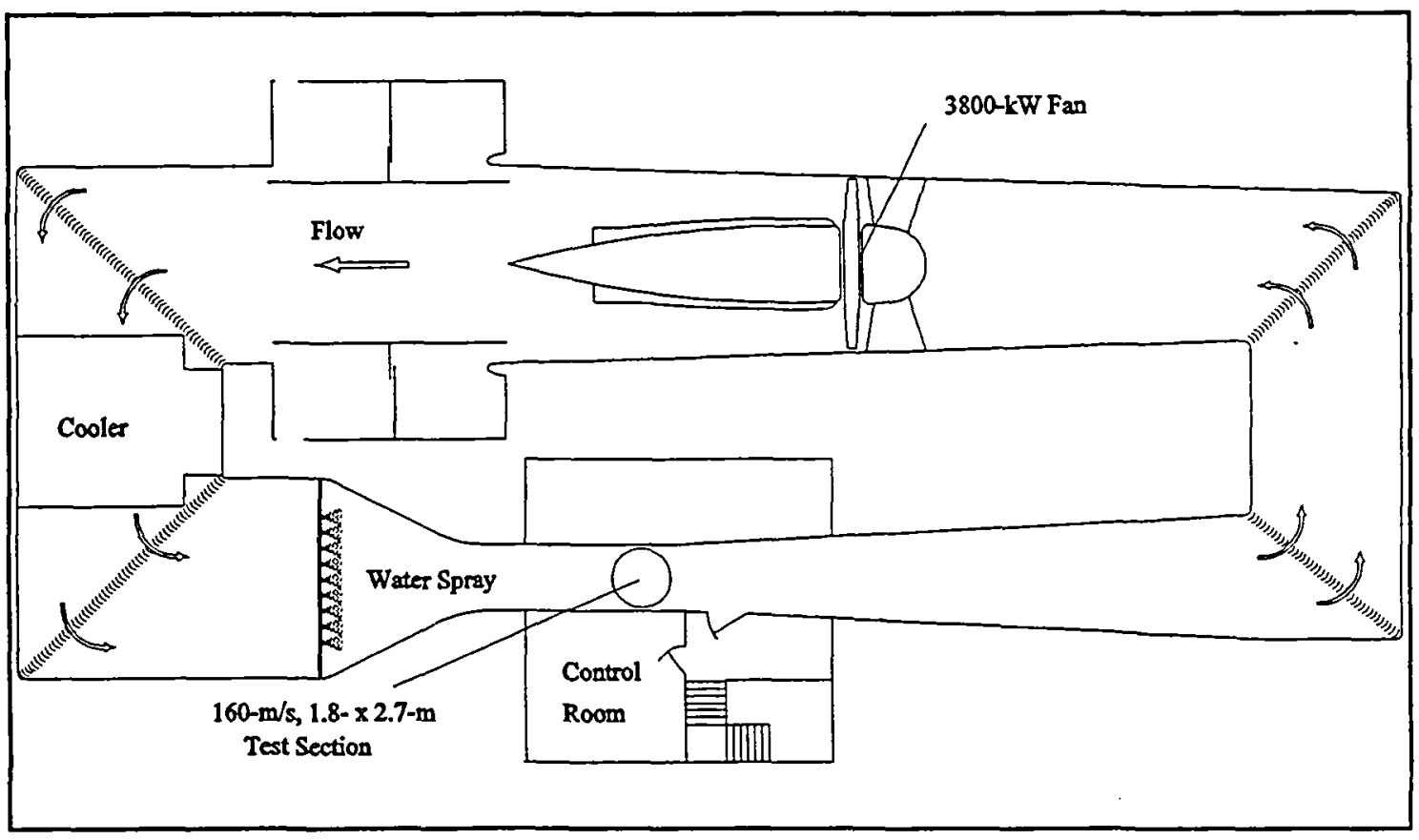

Figure 1. NASA Lewis Icing Research Tunnel (IRT). 


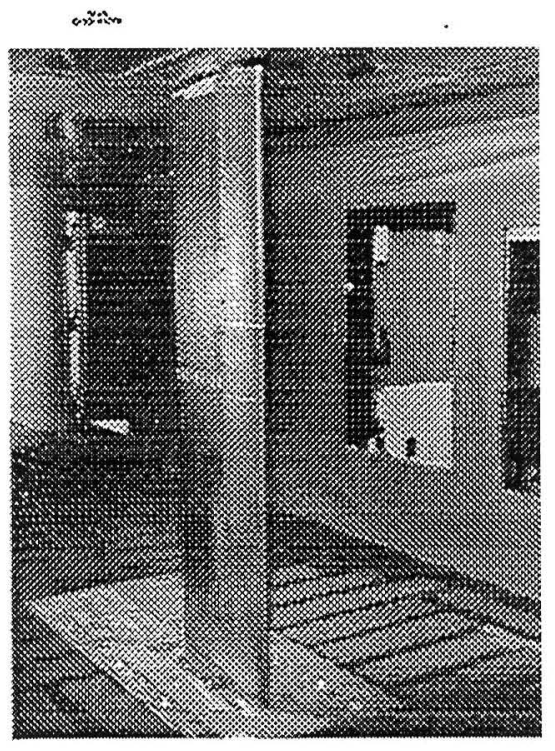

Figure 2. 53.3-cm- (21-in-) Chord NACA 0012 Airfoil Mounted in IRT Test Section.

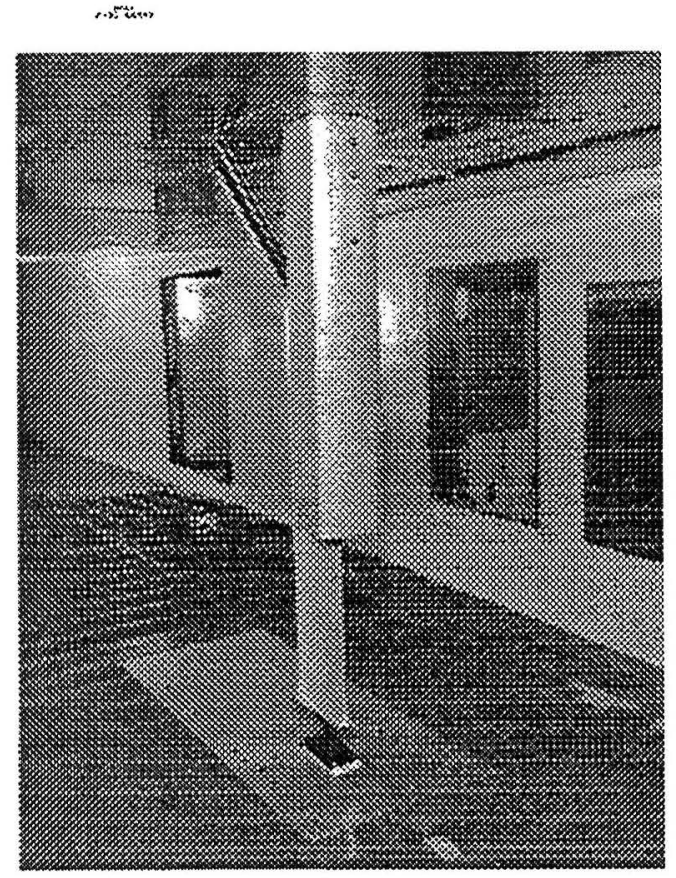

(a) Start-Up Shield in Raised (Testing) Position.

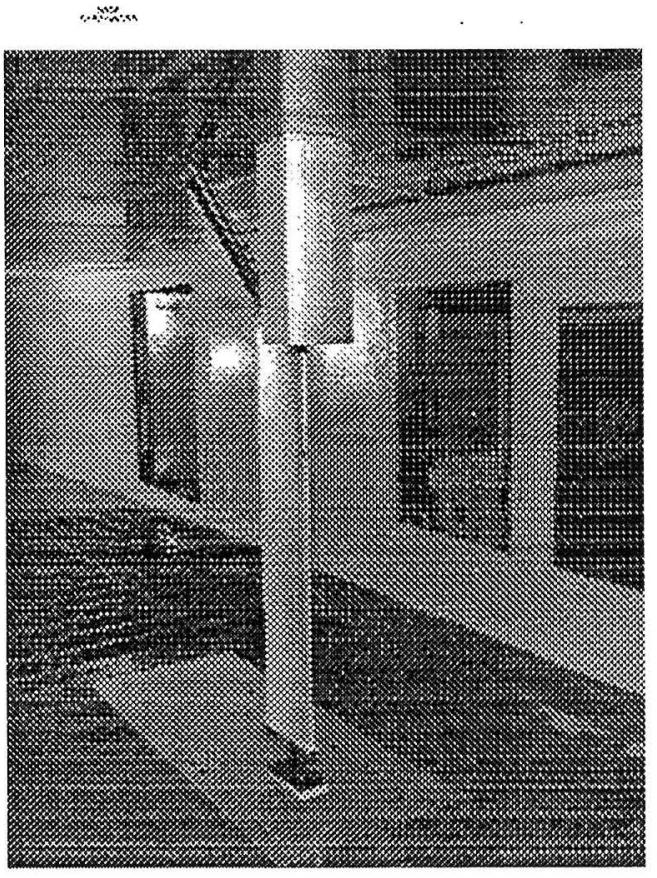

(b) Start-Up Shield in Lowered Position.

Figure 3. 26.7-cm- (10.5-in-) Chord NACA 0012 Airfoil. 


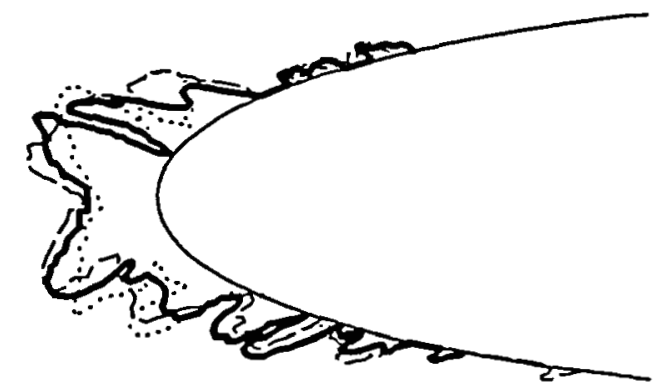

(a) Ice Shapes at Tunnel Centerline.

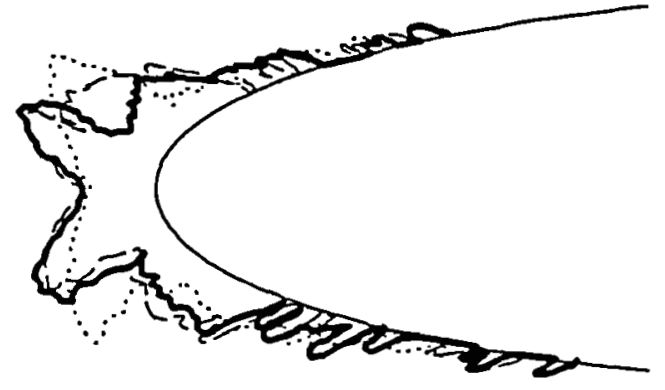

(b) Ice Shapes at $20 \mathrm{~cm}(8 \mathrm{in})$ Above Tunnel Centerline.

$\begin{array}{lccccccccc} & \boldsymbol{t}_{s t} & \boldsymbol{t}_{\text {tot }} & \boldsymbol{t}_{s t} & \boldsymbol{t}_{\text {sot }} & V & V & M V D & L W C & \tau \\ & { }^{\circ} \mathrm{C} & { }^{\circ} \mathrm{C} & { }^{\circ} \mathrm{F} & { }^{\circ} \mathrm{F} & \mathrm{m} / \mathrm{s} & \mathrm{mph} & \mu \mathrm{m} & \mathrm{g} / \mathrm{m}^{3} & \mathrm{~min} \\ \text { - Reference } & -12 & -10 & 10 & 14 & 67 & 150 & 30 & 1.00 & 7.3 \\ \text { - - Scaled to .8 Ref. LWC } & -12 & -10 & 11 & 15 & 67 & 150 & 30 & .80 & 9.1 \\ \text {...... Scaled to 1.4 Ref. LWC } & -12 & -10 & 11 & 15 & 67 & 150 & 30 & 1.40 & 5.2\end{array}$

Figure 4. LWCxtime Scaling Applied to Hom-Glaze Icing. Airfoil Chord, c, $53 \mathrm{~cm}(21 \mathrm{in})$.

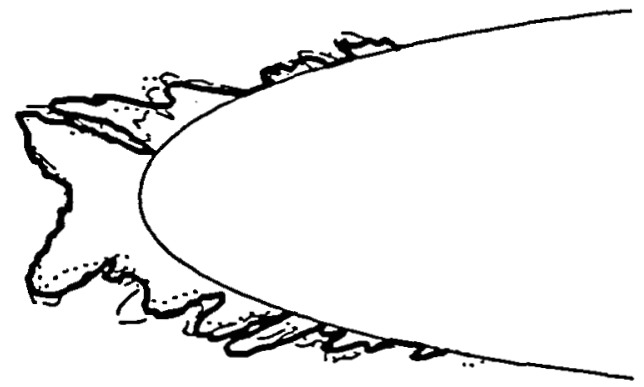

(a) Ice Shapes at Tunnel Centerline.

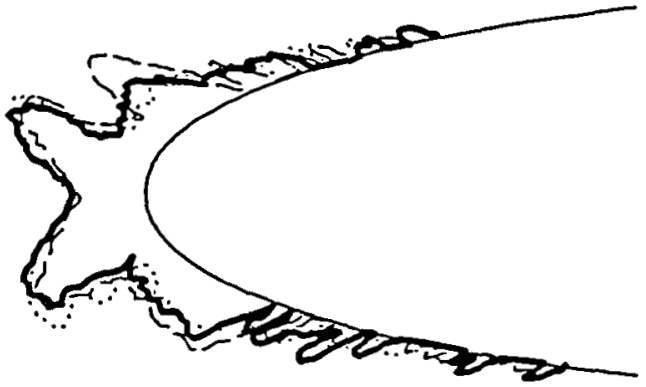

(b) Ice Shapes at $20 \mathrm{~cm}$ (8 in) Above Tunnel Centerline.

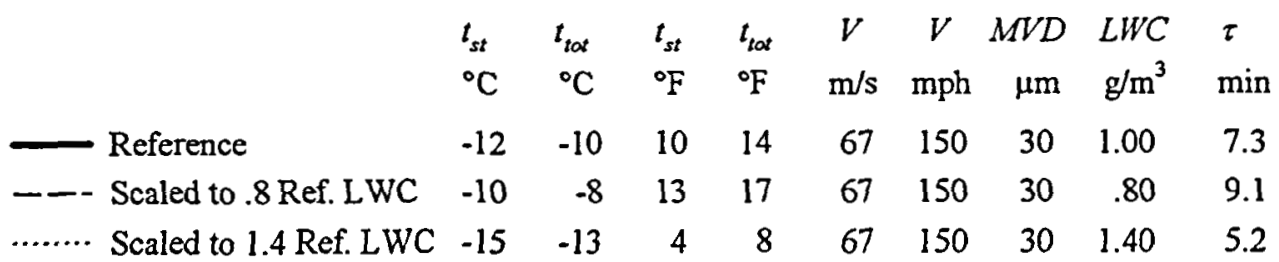

Figure 5. Olsen Scaling Applied to the Horn-Glaze Icing of Figure 4. Airfoil Chord, $c, 53 \mathrm{~cm}(21 \mathrm{in})$. 


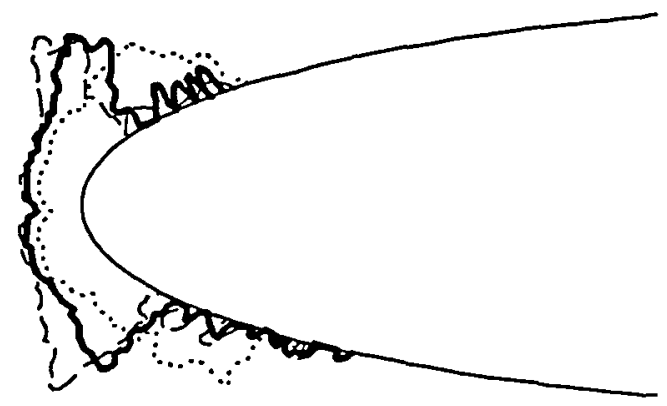

(a) Ice Shapes at Tunnel Centerline.

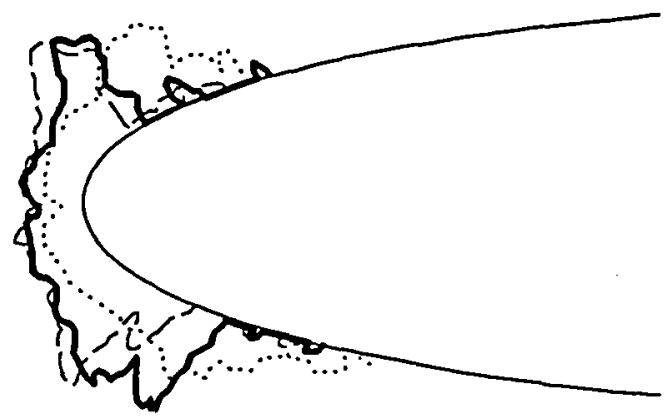

$\begin{array}{lccccccccc} & t_{s t} & \boldsymbol{t}_{\text {tot }} & \boldsymbol{t}_{s t} & \boldsymbol{t}_{\text {tot }} & V & V & M V D & L W C & \tau \\ & { }^{\circ} \mathrm{C} & { }^{\circ} \mathrm{C} & { }^{\circ} \mathrm{F} & { }^{\circ} \mathrm{F} & \mathrm{m} / \mathrm{s} & \mathrm{mph} & \mu \mathrm{m} & \mathrm{g} / \mathrm{m}^{3} & \mathrm{~min} \\ \text { - Reference } & -6 & -4 & 20 & 24 & 67 & 150 & 30 & 1.00 & 7.3 \\ \text { - - Scaled to .8 Ref. LWC } & -6 & -4 & 20 & 25 & 67 & 150 & 30 & .80 & 9.1 \\ \text {-..... Scaled to 1.4 Ref. LWC } & -6 & -4 & 21 & 25 & 67 & 149 & 30 & 1.40 & 5.2\end{array}$

Figure 6. LWCxTime Scaling Applied to Glaze Icing. Airfoil Chord, $c, 53 \mathrm{~cm}(21 \mathrm{in})$.

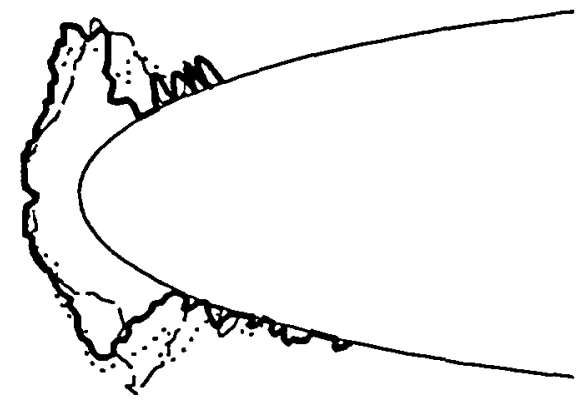

(a) Ice Shapes at Tunnel Centerline.

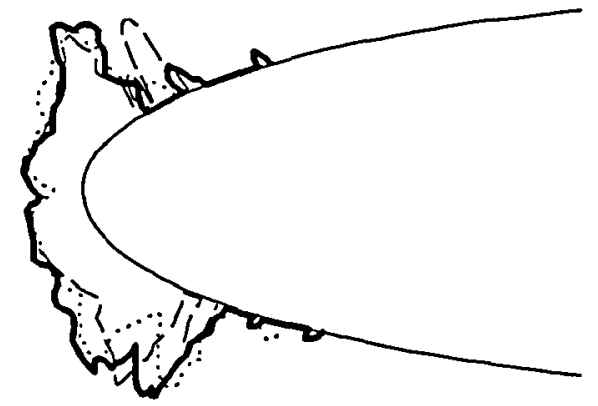

(b) Ice Shapes at $20 \mathrm{~cm}(8 \mathrm{in})$ Above Tunnel Centerline.

$\begin{array}{lccccccccc} & t_{\text {st }} & t_{\text {tot }} & t_{\text {st }} & t_{\text {tot }} & V & V & M V D & L W C & \tau \\ & { }^{\circ} \mathrm{C} & { }^{\circ} \mathrm{C} & { }^{\circ} \mathrm{F} & { }^{\circ} \mathrm{F} & \mathrm{m} / \mathrm{s} & \mathrm{mph} & \mu \mathrm{m} & \mathrm{g} / \mathrm{m}^{3} & \mathrm{~min} \\ \text { - Reference } & -6 & -4 & 20 & 24 & 67 & 150 & 30 & 1.00 & 7.3 \\ \text { - - Scaled to .8 Ref. LWC } & -5 & -3 & 22 & 26 & 67 & 150 & 30 & .80 & 9.1 \\ \text { ….. Scaled to 1.4 Ref. LWC } & -8 & -6 & 17 & 21 & 67 & 149 & 30 & 1.40 & 5.2\end{array}$

Figure 7. Olsen Scaling Applied to the Glaze Icing of Figure 6. Airfoil Chord, c, $53 \mathrm{~cm}(21 \mathrm{in})$. 


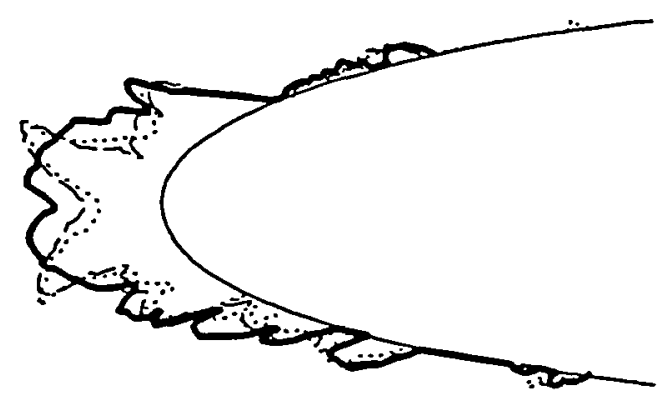

(a) Ice Shapes at Tunnel Centerline.

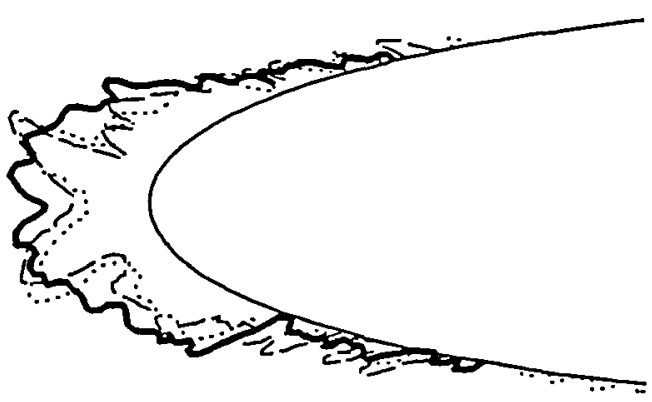

(b) Ice Shapes at $20 \mathrm{~cm}$ (8 in) Above Turnel Centerline.

$\begin{array}{lccccccccc} & t_{s t} & t_{\text {tot }} & t_{s t} & t_{\text {tot }} & V & V & M V D & L W C & \tau \\ & { }^{\circ} \mathrm{C} & { }^{\circ} \mathrm{C} & { }^{\circ} \mathrm{F} & { }^{\circ} \mathrm{F} & \mathrm{m} / \mathrm{s} & \mathrm{mph} & \mu \mathrm{m} & \mathrm{g} / \mathrm{m}^{3} & \mathrm{~min} \\ \text { - Reference } & -15 & -11 & 6 & 13 & 90 & 200 & 40 & .55 & 10.0 \\ \text { - - Scaled to 1.27 Ref. LWC }-15 & -11 & 6 & 13 & 90 & 200 & 40 & .70 & 7.8 \\ \text {-...... Scaled to 1.82 Ref. LWC }-15 & -11 & 6 & 13 & 89 & 200 & 40 & 1.00 & 5.5\end{array}$

Figure 8. LWCxTime Scaling Applied to Mixed Icing. Airfoil Chord, c, $53 \mathrm{~cm}(21 \mathrm{in})$.

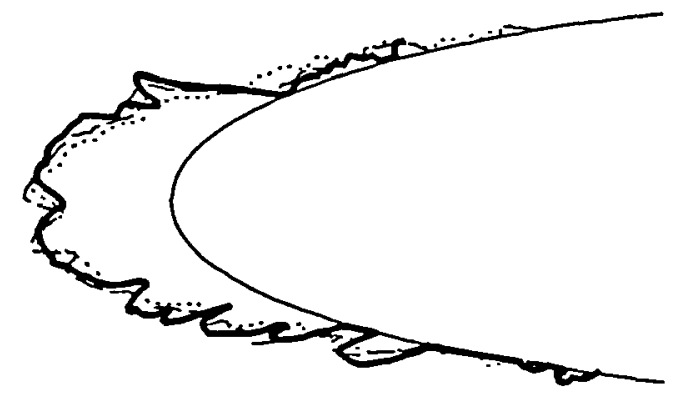

(a) Ice Shapes at Tunnel Centerline.

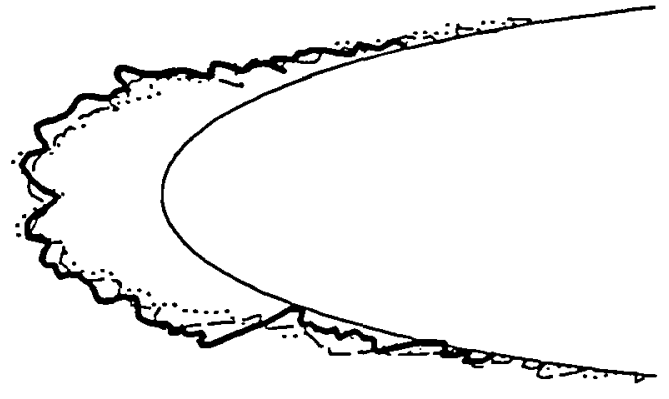

(b) Ice Shapes at $20 \mathrm{~cm}(8 \mathrm{in})$ Above Tunnel Centerline.

$\begin{array}{lcccccccc}t_{s t} & t_{\text {tot }} & t_{s t} & t_{\text {tot }} & V & V & M V D & L W C & \tau \\ { }^{\circ} \mathrm{C} & { }^{\circ} \mathrm{C} & { }^{\circ} \mathrm{F} & { }^{\circ} \mathrm{F} & \mathrm{m} / \mathrm{s} & \mathrm{mph} & \mu \mathrm{m} & \mathrm{g} / \mathrm{m}^{3} & \mathrm{~min} \\ -15 & -11 & 6 & 13 & 90 & 200 & 40 & .55 & 10.0 \\ -17 & -13 & 1 & 8 & 89 & 200 & 40 & .70 & 7.8 \\ -22 & -18 & -8 & -1 & 89 & 200 & 40 & 1.00 & 5.5\end{array}$

Figure 9. Olsen Scaling Applied to the Mixed Icing of Figure 8. Airfoil Chord, c, $53 \mathrm{~cm}(21 \mathrm{in})$. 


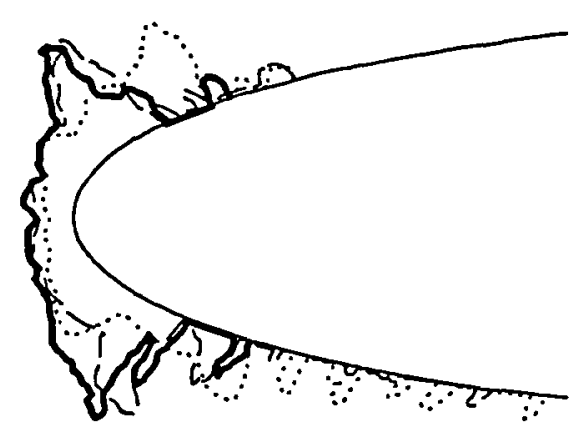

(a) Ice Shapes at Tunnel Centerline.

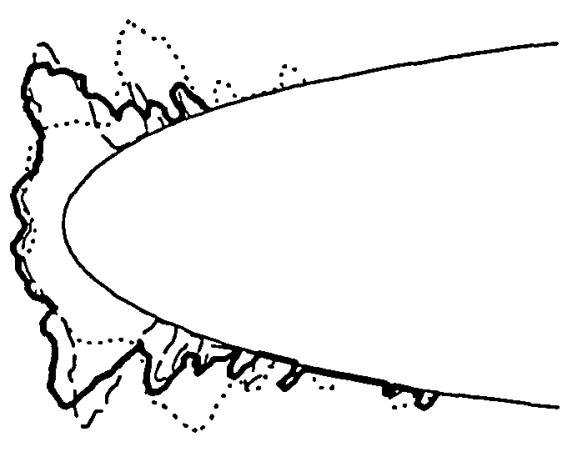

(b) Ice Shapes at $20 \mathrm{~cm}(8 \mathrm{in})$ Above Tunnel Centerline.

$\begin{array}{lccccccccc} & t_{s t} & t_{t o t} & t_{s t} & t_{t o t} & V & V & M W D & L W C & \tau \\ & { }^{\circ} \mathrm{C} & { }^{\circ} \mathrm{C} & { }^{\circ} \mathrm{F} & { }^{\circ} \mathrm{F} & \mathrm{m} / \mathrm{s} & \mathrm{mph} & \mu \mathrm{m} & \mathrm{g} / \mathrm{m}^{3} & \min \\ \text { - Reference } & -6 & -2 & 21 & 28 & 90 & 201 & 40 & .55 & 10.0 \\ \text { - - Scaled to } 1.27 L W C_{\mathrm{R}} & -6 & -2 & 21 & 28 & 90 & 200 & 40 & .70 & 7.8 \\ \text {-...... Scaled to } 1.82 L W C_{\mathrm{R}} & -6 & -2 & 21 & 28 & 89 & 200 & 40 & 1.00 & 5.5\end{array}$

Figure 10. LWCxTime Scaling Applied to Glaze Icing. Aiffoil Chord, $c, 53 \mathrm{~cm}(21 \mathrm{in})$.

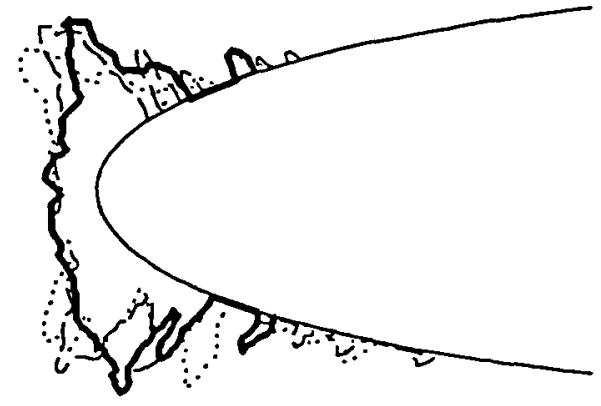

(a) Ice Shapes at Tunnel Centerline.

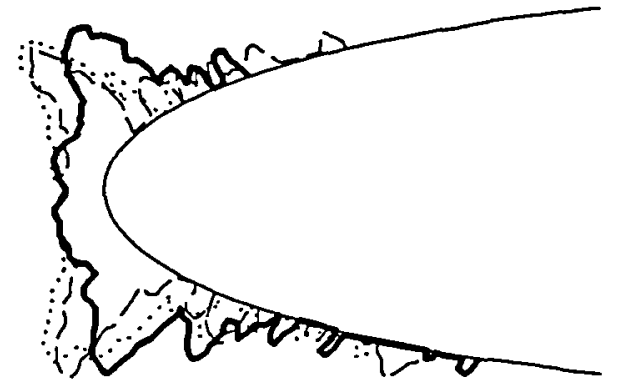

(b) Ice Shapes at $20 \mathrm{~cm}(8 \mathrm{in})$ Above Tunnel Centerline.

$\begin{array}{lccccccccc} & t_{s t} & t_{\text {tot }} & { }_{t_{s t}} & { }_{t} \text { tot } & V & V & M V D & L W C & \tau \\ & { }^{\circ} \mathrm{C} & { }^{\circ} \mathrm{C} & { }^{\circ} \mathrm{F} & { }^{\circ} \mathrm{F} & \mathrm{m} / \mathrm{s} & \mathrm{mph} & \mu \mathrm{m} & \mathrm{g} / \mathrm{m}^{3} & \mathrm{~min} \\ \text { - Reference } & -6 & -2 & 21 & 28 & 90 & 201 & 40 & .55 & 10.0 \\ \text { - - Scaled to } 1.27 L W C_{\mathrm{R}} & -7 & -3 & 19 & 26 & 89 & 200 & 40 & .70 & 7.8 \\ \text {-..... Scaled to } 1.82 L W C_{\mathrm{R}} & -9 & -5 & 16 & 23 & 89 & 200 & 40 & 1.00 & 5.5\end{array}$

Figure 11. Olsen Scaling Applied to the Glaze Icing of Figure 10. Airfoil Chord, c, $53 \mathrm{~cm}(21 \mathrm{in})$. 

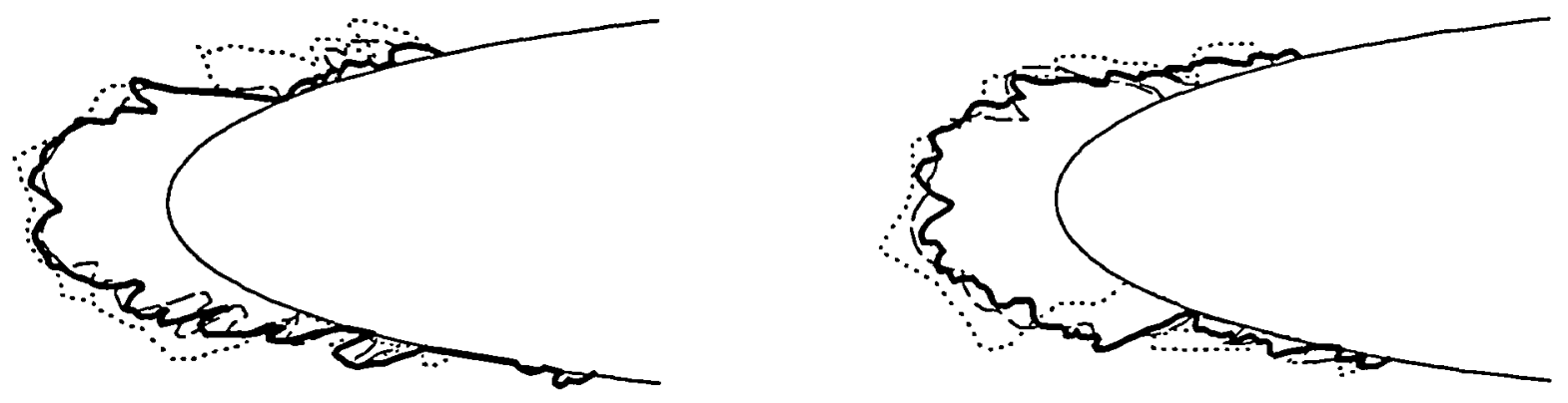

(a) Ice Shapes at Tunnel Centerline.

(b) Ice Shapes at $20 \mathrm{~cm}$ ( 8 in) Above Tunnel Centerline.

\begin{tabular}{lccccccccccc} 
& \multicolumn{2}{c}{ chord } & $t_{s t}$ & $t_{\text {tot }}$ & ${ }^{t_{s t}}$ & $t_{\text {tot }}$ & $V$ & $V$ & $M V D$ & $L W C$ & $\tau$ \\
& $\mathrm{cm}$ & in & ${ }^{\circ} \mathrm{C}$ & ${ }^{\circ} \mathrm{C}$ & ${ }^{\circ} \mathrm{F}$ & ${ }^{\circ} \mathrm{F}$ & $\mathrm{m} / \mathrm{s}$ & $\mathrm{mph}$ & $\mu \mathrm{m}$ & $\mathrm{g} / \mathrm{m}^{3}$ & \multicolumn{1}{c}{$\min$} \\
\hline - Reference & 53.3 & 21 & -15 & -11 & 6 & 13 & 90 & 200 & 40 & .55 & 10.0 \\
- A... AEDC 1/2 Scale & 26.7 & 10.5 & -15 & -11 & 6 & 13 & 89 & 200 & 26 & .78 & 3.5 \\
AEDC 1/3 Scale & 17.8 & 7 & -15 & -11 & 6 & 13 & 89 & 200 & 20 & .95 & 1.9
\end{tabular}

Figure 12. AEDC Scaling Applied to NACA 0012 Airfoils. Case 1 in Table II.

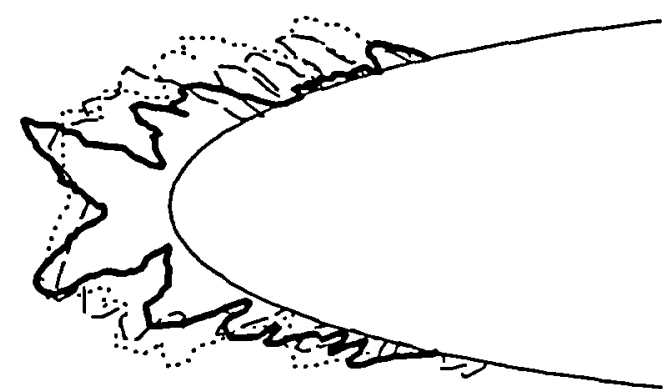

(a) Ice Shapes at Tunnel Centerline.

\begin{tabular}{ccccccccccc}
\multicolumn{2}{c}{ chord } & $t_{s t}$ & $t_{\text {tot }}$ & $t_{s t}$ & $t_{\text {tot }}$ & $V$ & $V$ & $M V D$ & $L W C$ & $\tau$ \\
$\mathrm{cm}$ & in & ${ }^{\circ} \mathrm{C}$ & ${ }^{\circ} \mathrm{C}$ & ${ }^{\circ} \mathrm{F}$ & ${ }^{\circ} \mathrm{F}$ & $\mathrm{m} / \mathrm{s}$ & $\mathrm{mph}$ & $\mu \mathrm{m}$ & $\mathrm{g} / \mathrm{m}^{3}$ & $\mathrm{~min}$ \\
53.3 & 21 & -12 & -8 & 10 & 17 & 90 & 200 & 40 & .55 & 10.0 \\
26.7 & 10.5 & -12 & -8 & 11 & 18 & 90 & 200 & 26 & .77 & 3.5 \\
17.8 & 7 & -12 & -8 & 10 & 18 & 90 & 200 & 20 & .95 & 1.9
\end{tabular}

Figure 13. AEDC Scaling Applied to NACA 0012 Airfoils. Case 2 in Table II. 


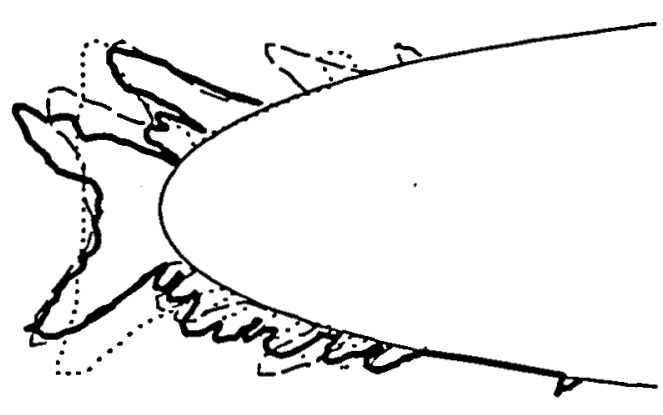

(a) Ice Shapes at Tunnel Centerline.

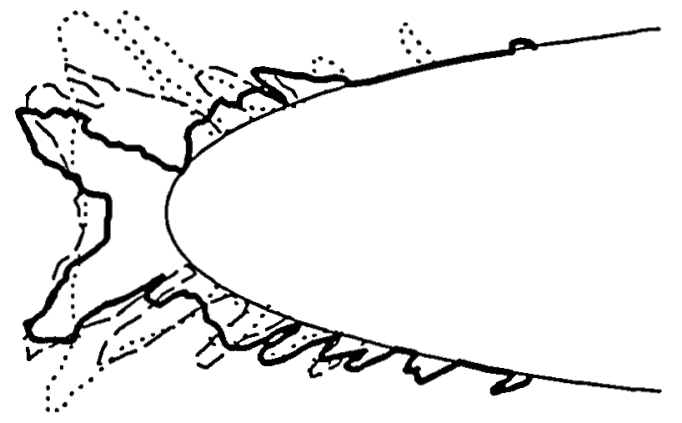

(b) Ice Shapes at $20 \mathrm{~cm}(8 \mathrm{in})$ Above Tunnel Centerline.

\begin{tabular}{|c|c|c|c|c|c|c|c|c|c|c|c|}
\hline & \multicolumn{2}{|c|}{ chord } & \multirow{2}{*}{$\begin{array}{l}t_{s t} \\
{ }^{\circ} \mathrm{C}\end{array}$} & \multirow{2}{*}{$\begin{array}{l}t_{t o t} \\
{ }^{\circ} \mathrm{C}\end{array}$} & \multirow{2}{*}{$\begin{array}{l}t_{s t} \\
{ }^{\circ} \mathrm{F}\end{array}$} & \multirow{2}{*}{$\begin{array}{l}t_{t o t} \\
{ }^{\circ} \mathrm{F}\end{array}$} & \multirow{2}{*}{$\begin{array}{c}V \\
\mathrm{~m} / \mathrm{s}\end{array}$} & \multirow{2}{*}{$\begin{array}{c}V \\
\mathrm{mph}\end{array}$} & \multirow{2}{*}{$\begin{array}{r}M V D \\
\mu \mathrm{m}\end{array}$} & \multirow{2}{*}{$\begin{array}{l}L W C \\
\mathrm{~g} / \mathrm{m}^{3}\end{array}$} & \multirow{2}{*}{$\begin{array}{l}\tau \\
\min \end{array}$} \\
\hline & $\mathrm{cm}$ & in & & & & & & & & & \\
\hline & 53.3 & 21 & -9 & -5 & 16 & 23 & 89 & 200 & 41 & .55 & 10.0 \\
\hline & 26.7 & 10.5 & -9 & -5 & 15 & 23 & 90 & 201 & 26 & .77 & 3.5 \\
\hline AEDC 1/3 Scale & 17.8 & 7 & -9 & -5 & 16 & 23 & 89 & 199 & 20 & .95 & 1.9 \\
\hline
\end{tabular}

Figure 14. AEDC Scaling Applied to NACA 0012 Airfoils. Case 3 in Table II.

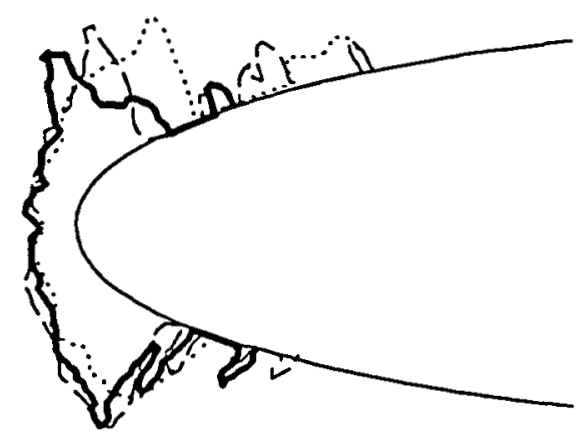

(a) Ice Shapes at Tunnel Centerline.

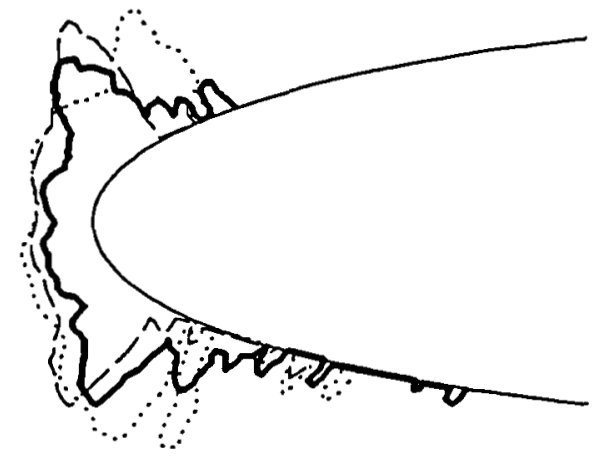

(b) Ice Shapes at $20 \mathrm{~cm}(8$ in) Above Tunnel Centerline.

\begin{tabular}{|c|c|c|c|c|c|c|c|c|c|c|c|}
\hline & \multicolumn{2}{|c|}{ chord } & $t_{s t}$ & $t_{\text {tog }}$ & $t_{s t}$ & $t_{\text {tot }}$ & $V$ & $V$ & $M V D$ & $L W C$ & $\tau$ \\
\hline & $\mathrm{cm}$ & in & ${ }^{\circ} \mathrm{C}$ & ${ }^{\circ} \mathrm{C}$ & ${ }^{\circ} \mathrm{F}$ & ${ }^{\circ} \mathrm{F}$ & $\mathrm{m} / \mathrm{s}$ & $\mathrm{mph}$ & $\mu \mathrm{m}$ & $\mathrm{g} / \mathrm{m}^{3}$ & $\min$ \\
\hline Reference & 53.3 & 21 & -6 & -2 & 21 & 28 & 90 & 201 & 40 & .55 & 10.0 \\
\hline cale & 26.7 & 10.5 & -6 & -2 & 21 & 28 & 89 & 200 & 26 & .78 & 3.5 \\
\hline AEDC $1 / 3$ Scale & 17.8 & 7 & -6 & -2 & 21 & 28 & 90 & 200 & 20 & .95 & 1.9 \\
\hline
\end{tabular}

Figure 15. AEDC Scaling Applied to NACA 0012 Airfoils. Case 4 in Table II. 


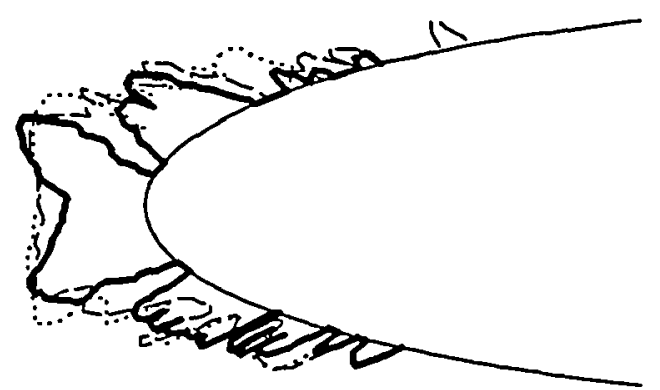

(a) Ice Shapes at Tunnel Centerline.

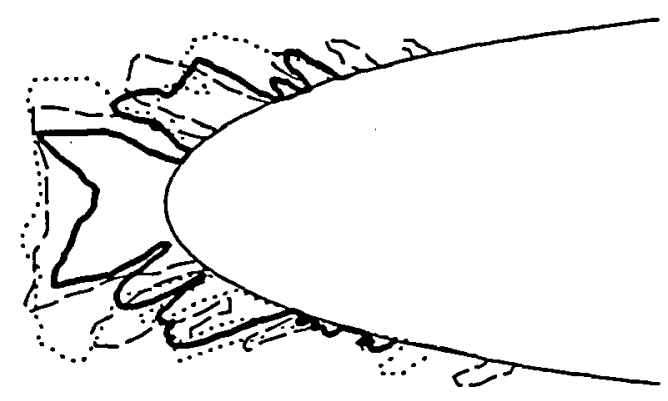

(b) Ice Shapes at $20 \mathrm{~cm}(8 \mathrm{in})$ Above Tunnel Centerline.

\begin{tabular}{lccccccccccc} 
& \multicolumn{2}{c}{ chord } & $t_{s t}$ & $t_{\text {tot }}$ & $t_{s t}$ & $t_{\text {tot }}$ & $V$ & $V$ & $M V D$ & $L W C$ & $\tau$ \\
& $\mathrm{cm}$ & in & ${ }^{\circ} \mathrm{C}$ & ${ }^{\circ} \mathrm{C}$ & ${ }^{\circ} \mathrm{F}$ & ${ }^{\circ} \mathrm{F}$ & $\mathrm{m} / \mathrm{s}$ & $\mathrm{mph}$ & $\mu \mathrm{m}$ & $\mathrm{g} / \mathrm{m}^{3}$ & $\mathrm{~min}$ \\
\hline - Reference & 53.3 & 21 & -11 & -8 & 13 & 17 & 67 & 150 & 41 & .65 & 11.2 \\
- - AEDC 1/2 Scale & 26.7 & 10.5 & -11 & -9 & 12 & 16 & 67 & 150 & 26 & .92 & 4.0 \\
AEDC 1/3 Scale & 17.8 & 7 & -11 & -9 & 12 & 16 & 67 & 149 & 20 & 1.13 & 2.2
\end{tabular}

Figure 16. AEDC Scaling Applied to NACA 0012 Airfoils. Case 5 in Table II.

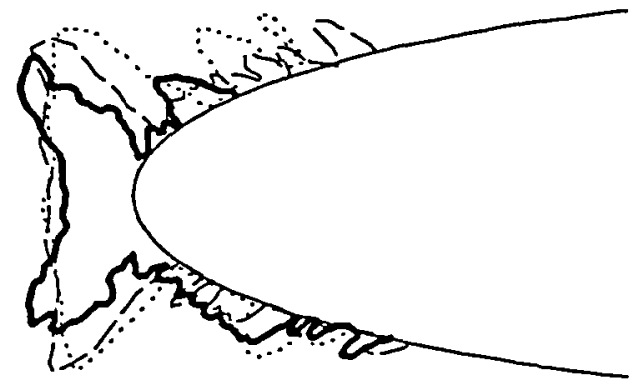

(a) Ice Shapes at Tunnel Centerline.

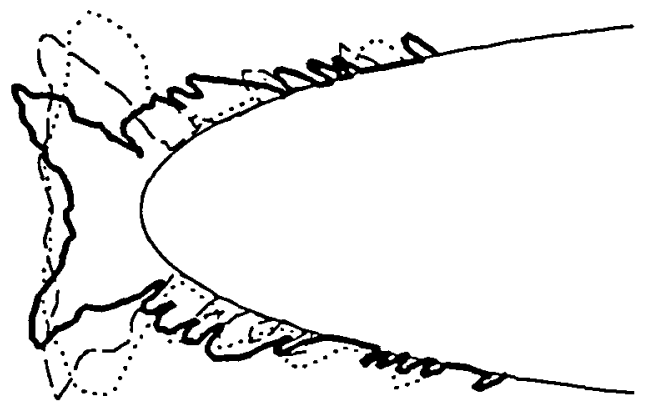

(b) Ice Shapes at $20 \mathrm{~cm}(8 \mathrm{in})$ Above Tunnel Centerline.

\begin{tabular}{lccccccccccc} 
& \multicolumn{2}{c}{ chord } & $t_{s t}$ & $t_{\text {tot }}$ & $t_{s t}$ & $t_{\text {tot }}$ & $V$ & $V$ & $M V D$ & $L W C$ & $\tau$ \\
& $\mathrm{cm}$ & in & ${ }^{\circ} \mathrm{C}$ & ${ }^{\circ} \mathrm{C}$ & ${ }^{\circ} \mathrm{F}$ & ${ }^{\circ} \mathrm{F}$ & $\mathrm{m} / \mathrm{s}$ & $\mathrm{mph}$ & $\mu \mathrm{m}$ & $\mathrm{g} / \mathrm{m}^{3}$ & $\mathrm{~min}$ \\
\hline - Reference & 53.3 & 21 & -8 & -6 & 17 & 21 & 67 & 150 & 41 & .65 & 11.2 \\
-..... AEDC 1/2 Scale & 26.7 & 10.5 & -8 & -6 & 18 & 22 & 67 & 150 & 26 & .92 & 4.0 \\
AEDC 1/3 Scale & 17.8 & 7 & -8 & -6 & 18 & 22 & 67 & 151 & 20 & 1.12 & 2.1
\end{tabular}

Figure 17. AEDC Scaling Applied to NACA 0012 Airfoils. Case 6 in Table II. 


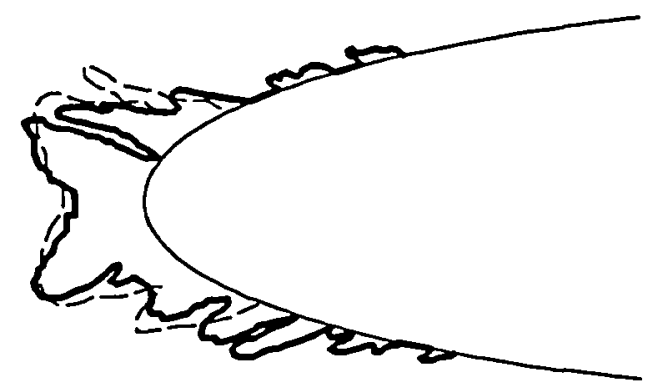

(a) Ice Shapes at Tunnel Centerline.

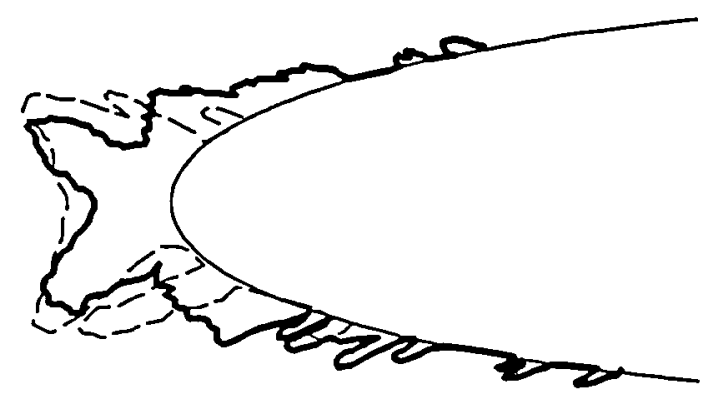

(b) Ice Shapes at $20 \mathrm{~cm}(8$ in) Above Tunnel Centerline.

\begin{tabular}{lccccccccccc} 
& chord & $t_{s t}$ & $t_{\text {tot }}$ & $t_{s t}$ & $t_{\text {tot }}$ & $V$ & $V$ & $M V D$ & $L W C$ & $\tau$ \\
& $\mathrm{cm}$ & in & ${ }^{\circ} \mathrm{C}$ & ${ }^{\circ} \mathrm{C}$ & ${ }^{\circ} \mathrm{F}$ & ${ }^{\circ} \mathrm{F}$ & $\mathrm{m} / \mathrm{s}$ & $\mathrm{mph}$ & $\mu \mathrm{m}$ & $\mathrm{g} / \mathrm{m}^{3}$ & $\mathrm{~min}$ \\
& 53.3 & 21 & -12 & -10 & 10 & 14 & 67 & 150 & 30 & 1.00 & 7.3 \\
\hline$-1 / 2$ Scale & 26.7 & 10.5 & -9 & -6 & 15 & 22 & 88 & 197 & 17 & .80 & 3.5
\end{tabular}

Figure 18. Hybrid Scaling Combining Constant-We With Olsen Method. NACA 0012 Airfoils. Case I in Table III.

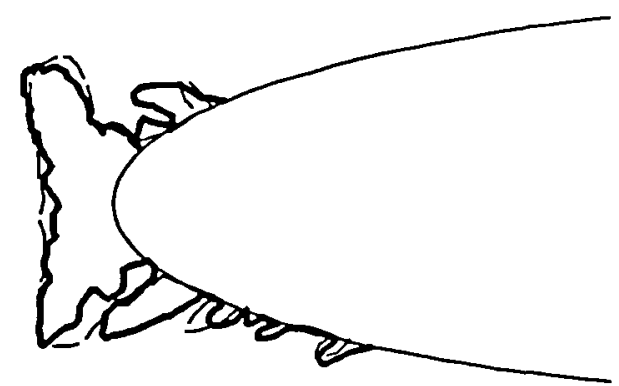

(a) Ice Shapes at Tunnel Centerline.

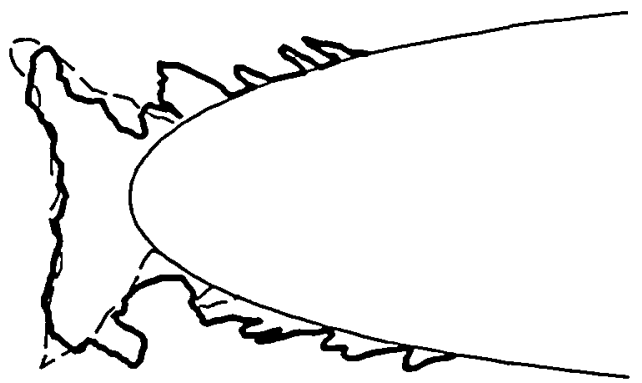

(b) Ice Shapes at $20 \mathrm{~cm}(8 \mathrm{in})$ Above Tunnel Centerline.

\begin{tabular}{lccccccccccc} 
& chord & $t_{s t}$ & $t_{\text {tot }}$ & ${ }^{t_{s t}}$ & $t_{\text {tot }}$ & $V$ & $V$ & $M V D$ & $L W C$ & $\tau$ \\
& $\mathrm{cm}$ & in & ${ }^{\circ} \mathrm{C}$ & ${ }^{\circ} \mathrm{C}$ & ${ }^{\circ} \mathrm{F}$ & ${ }^{\circ} \mathrm{F}$ & $\mathrm{m} / \mathrm{s}$ & $\mathrm{mph}$ & $\mu \mathrm{m}$ & $\mathrm{g} / \mathrm{m}^{3}$ & $\mathrm{~min}$ \\
\hline - Reference & 53.3 & 21 & -10 & -7 & 15 & 19 & 67 & 150 & 30 & 1.00 & 7.3 \\
$-1 / 2$ Scale & 26.7 & 10.5 & -7 & -4 & 19 & 26 & 88 & 196 & 18 & .80 & 3.5
\end{tabular}

Figure 19. Hybrid Scaling Combining Constant-We With Olsen Method. NACA 0012 Airfoils. Case 2 in Table III. 
Public reporting burden for this collection of information is estimated to average 1 hour per response, inclucing the time for reviewing instructions, searching existing data sources, gathering and maintaining the data needed, and completing and reviewing the collection of information. Send comments regarding this burden estimate or any other aspect of this collection of information, including suggestions for reducing this burden, to Washington Headquarters Sevices, Directorate for Information Operations and Reports, 1215 Jefferson Davis Highway, Suite 1204, Arlington. VA 22202-4302, and to the Otfice of Managernent and Budget, Paperwork Reduction Project (0704-0188). Washington. DC 20503.

\begin{tabular}{|l|l|l} 
1. AGENCY USE ONLY (Leave blank) & $\begin{array}{c}\text { 2. REPORT DATE } \\
\text { January } 1996\end{array}$ & $\begin{array}{r}\text { 3. REPORT TYPE AND DATES COVERED } \\
\text { Technical Memorandum }\end{array}$ \\
\hline
\end{tabular}

4. TITLE AND SUBTIRLE

5. FUNDING NUMBERS

Further Evaluation of Traditional Icing Scaling Methods

6. AUTHOR(S)

WU-505-68-10

David N. Anderson

7. PERFORMING ORGANIZATION NAME(S) AND ADDRESS(ES)

8. PERFORMING ORGANIZATION REPORT NUMBER

National Aeronautics and Space Administration

Lewis Research Center

Cleveland, Ohio 44135-3191

E-10070

9. SPONSORING/MONITORING AGENCY NAME(S) AND ADDRESS(ES)

10. SPONSORING/MONITORING AGENCY REPORT NUMBER

National Aeronautics and Space Administration

Washington, D.C. 20546-0001

NASA TM-107140

AIAA-96-0633

11. SUPPLEMENTARY NOTES

Prepared for the 34th Aerospace Sciences Meeting and Exhibit sponsored by the American Institute of Aeronautics and Astronautics, Reno, Nevada, January 15-18, 1996. Responsible person, David N. Anderson, organization code 2720, (216) 433-3585.

12a. DISTRIBUTIONAVAILABILTYY STATEMENT 12b. DISTRIBUTION CODE

Unclassified -Unlimited

Subject Category 03

This publication is available from the NASA Center for Aerospace Information, (301) 621-0390.

13. ABSTRACT (Maximum 200 words)

This report provides additional evaluations of two methods to scale icing test conditions; it also describes a hybrid technique for use when scaled conditions are outside the operating envelope of the test facility. The first evaluation is of the Olsen method which can be used to scale the liquid-water content in icing tests, and the second is the AEDC (Ruff) method which is used when the test model is less than full size. Equations for both scaling methods are presented in the paper, and the methods were evaluated by performing icing tests in the NASA Lewis Icing Research Tunnel (IRT). The Olsen method was tested using 53-cm-diameter NACA 0012 airfoils. Tests covered liquid-water-contents which varied by as much as a factor of 1.8. The Olsen method was generally effective in giving scale ice shapes which matched the reference shapes for these tests. The AEDC method was tested with NACA 0012 airfoils with chords from $18 \mathrm{~cm}$ to 53 $\mathrm{cm}$. The 53-cm-chord airfoils were used in reference tests, and 1/2-and 1/3-scale tests were made at conditions determined by applying the AEDC scaling method. The scale and reference airspeeds were matched in these tests. The AEDC method was found to provide fairly effective scaling for $1 / 2$-size tests, but for $1 / 3$-size models, scaling was generally less effective. In addition to these two scaling methods, a hybrid approach was also tested in which the Olsen method was used to adjust the $L W C$ after size was scaled using the constant-Weber-number method. This approach was found to be an effective way to test when scaled conditions would otherwise be outside the capability of the test facility.

\begin{tabular}{|c|c|}
\hline $\begin{array}{c}\text { 14. SUBJECT TERMS } \\
\text { Scaling; Icing }\end{array}$ \\
\hline $\begin{array}{c}\text { 17. SECURTY CLASSIFICATION } \\
\text { OF REPORT } \\
\text { Unclassified }\end{array}$ & $\begin{array}{c}\text { 18. SECURTY CLASSIFICATION } \\
\text { OF THIS PAGE } \\
\text { Unclassified }\end{array}$ \\
\hline
\end{tabular}

\begin{tabular}{|l|c|}
\hline & $\begin{array}{c}\text { 15. NUMBER OF PAGES } \\
20\end{array}$ \\
\cline { 2 - 2 } & $\begin{array}{c}\text { 16. PRICE CODE } \\
\text { A03 }\end{array}$ \\
\hline $\begin{array}{c}\text { 19. SECURITY CLASSIFICATION } \\
\text { OF ABSTRACT } \\
\text { Unclassified }\end{array}$ & $\begin{array}{l}\text { 20. LIMITATION OF ABSTRACT } \\
\text { Und }\end{array}$ \\
\hline
\end{tabular}


National Aeronautics and

Space Administration

Lewis Research Center

21000 Brookpark Rd.

Cleveland, $\mathrm{OH}$ 44135-3191

Official Business

Penally for Private Use $\$ 300$

POSTMASTER: If Undeliverable — Do Not Return 